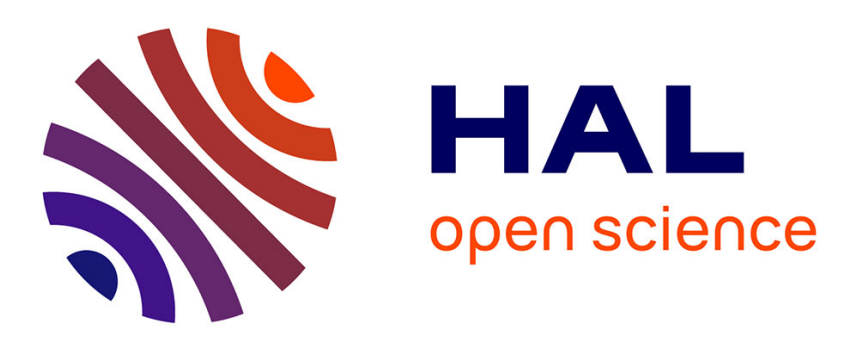

\title{
Anisotropic mechanical and functional properties of graphene-based alumina matrix nanocomposites
}

Yasemin Çelik, Ali Çelik, Emmanuel Flahaut, Ender Suvaci

\section{To cite this version:}

Yasemin Çelik, Ali Çelik, Emmanuel Flahaut, Ender Suvaci. Anisotropic mechanical and functional properties of graphene-based alumina matrix nanocomposites. Journal of the European Ceramic Society, 2016, 36 (8), pp. 2075-2086. 10.1016/j.jeurceramsoc.2016.02.032 . hal-01451008v2

\section{HAL Id: hal-01451008 \\ https://hal.science/hal-01451008v2}

Submitted on 21 Feb 2017

HAL is a multi-disciplinary open access archive for the deposit and dissemination of scientific research documents, whether they are published or not. The documents may come from teaching and research institutions in France or abroad, or from public or private research centers.
L'archive ouverte pluridisciplinaire HAL, est destinée au dépôt et à la diffusion de documents scientifiques de niveau recherche, publiés ou non, émanant des établissements d'enseignement et de recherche français ou étrangers, des laboratoires publics ou privés. 


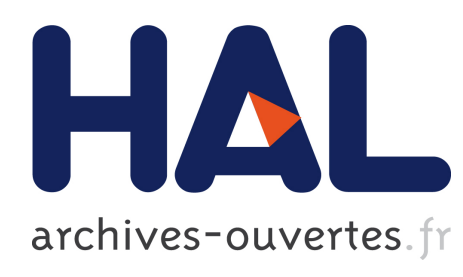

\section{Anisotropic mechanical and functional properties of graphene-based alumina matrix nanocomposites}

Yasemin Çelik, Ali Çelik, Emmanuel Flahaut, Ender Suvacı

\section{To cite this version:}

Yasemin Çelik, Ali Çelik, Emmanuel Flahaut, Ender Suvacı. Anisotropic mechanical and functional properties of graphene-based alumina matrix nanocomposites. Journal of the European Ceramic Society, Elsevier, 2016, vol. 36 (n8), pp. 2075-2086. $<10.1016 /$ j.jeurceramsoc.2016.02.032>. $<$ hal-01451008 $>$

\section{HAL Id: hal-01451008 \\ https://hal.archives-ouvertes.fr/hal-01451008}

Submitted on 31 Jan 2017

HAL is a multi-disciplinary open access archive for the deposit and dissemination of scientific research documents, whether they are published or not. The documents may come from teaching and research institutions in France or abroad, or from public or private research centers.
L'archive ouverte pluridisciplinaire HAL, est destinée au dépôt et à la diffusion de documents scientifiques de niveau recherche, publiés ou non, émanant des établissements d'enseignement et de recherche français ou étrangers, des laboratoires publics ou privés. 


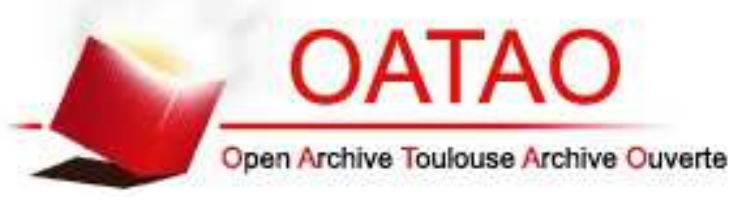

\section{Open Archive TOULOUSE Archive Ouverte (OATAO)}

OATAO is an open access repository that collects the work of Toulouse researchers and makes it freely available over the web where possible.

This is an author-deposited version published in : http://oatao.univ-toulouse.fr/ Eprints ID : 16742

To link to this article : DOI:10.1016/j.jeurceramsoc.2016.02.032URL

URL : http://dx.doi.org/10.1016/j.jeurceramsoc.2016.02.032

To cite this version : Çelik, Yasemin and Çelik, Ali and

Flahaut, Emmanuel and Suvac1, Ender Anisotropic mechanical and functional properties of graphene-based alumina matrix

nanocomposites. (2016) Journal of the European Ceramic Society, vol. 36 (n॰8). pp. 2075-2086. ISSN 0955-2219

Any correspondence concerning this service should be sent to the repository administrator: staff-oatao@ listes-diff.inp-toulouse.fr 


\title{
Anisotropic mechanical and functional properties of graphene-based alumina matrix nanocomposites
}

\author{
Y. Çelik ${ }^{\mathrm{a}, \mathrm{b}, *}$, A. Çelik ${ }^{\mathrm{a}}$, E. Flahaut ${ }^{\mathrm{b}, \mathrm{c}}$, E. Suvaci ${ }^{\mathrm{a}}$ \\ a Anadolu University, Department of Materials Science and Engineering, 26480 Eskisehir, Turkey

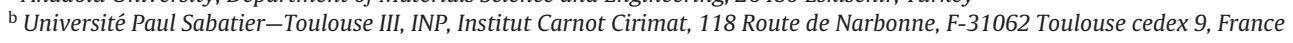 \\ ${ }^{\mathrm{c}}$ CNRS, Institut Carnot Cirimat, F-31062 Toulouse, France
}

\section{Keywords:}

Anisotropy

Graphene platelets $/ \mathrm{Al}_{2} \mathrm{O}_{3}$ nanocomposites

Mechanical properties

Electrical conductivity

Thermal conductivity

\begin{abstract}
A B S T R A C T
Graphene platelets (GPLs) containing $\mathrm{Al}_{2} \mathrm{O}_{3}$ nanocomposites, which exhibit anisotropic microstructure, have been prepared by spark plasma sintering (SPS), and effects of this anisotropy on mechanical, electrical and thermal properties of the nanocomposites have been investigated. 3 vol.\% GPLs addition into monolithic $\mathrm{Al}_{2} \mathrm{O}_{3}$ caused fracture toughness $\left(K_{\mathrm{Ic}}\right)$ to increase by $26.7 \%$ in the in-plane direction and to decrease by $17.2 \%$ in the through thickness direction. $K_{\mathrm{Ic}}$ started to decrease in the in-plane direction and to increase in the through-thickness direction with further increase in the GPLs amount. The electrical conductivity of the nanocomposites exhibited a slight anisotropy with a lower resistivity in the in-plane direction. Oriented GPLs also led to a less resistive heat conduction path in the in-plane direction. $\sim 44 \%$ increase in the in-plane thermal conductivity was achieved at $600^{\circ} \mathrm{C}$ with $15 \mathrm{vol} . \%$ GPLs addition into the monolithic $\mathrm{Al}_{2} \mathrm{O}_{3}$ and this resulted in $\sim 52 \%$ increase in the $k_{\text {in-plane }} / k_{\text {through-thickness }}$ ratio.
\end{abstract}

\section{Introduction}

Nanocomposites, which exhibit superior mechanical and physical properties compared to their respective matrix materials, are among the most technologically promising materials to meet the worldwide demand for high performance applications in many fields. In that respect, development of novel nanocomposites with improved properties plays a critical role to extend their use in industry.

Carbon-based fillers, especially carbon nanotubes (CNTs), have been widely utilized in nanocomposite research in order to improve structural and functional properties of various host materials [1-3]. Graphene-based materials are also promising candidates as filler materials in nanocomposites due to their unique combination of outstanding mechanical properties and exceptionally high thermal and electrical conductivities, as well as their two dimensional nature and high aspect ratio. Studies on nanocomposites containing graphene-based materials have been mainly focused on polymer matrices and it has been shown that significant multifunctional property enhancements are possible even at low

\footnotetext{
* Corresponding author at: Anadolu University, Department of Materials Science and Engineering, 26480 Eskisehir, Turkey.

E-mail address: ybozkaya@anadolu.edu.tr (Y. Çelik).
}

filler contents. Recent achievements and advances in graphenebased polymer matrix composites have been reviewed by many authors [4,5]. However, potential of graphene-based fillers also in ceramic-matrix nanocomposites has been realized in recent years. Although high mechanical strength, thermal resistance and good chemical stability of monolithic ceramics make them promising materials for high technology applications such as electronics, defense, aerospace and transportation, their brittle and electrically insulating nature limit their use in these potential applications. Wear resistant and structural materials for extreme environments, such as high temperature/pressure, nuclear radiation, and chemicals, are required to be both strong and tough [6]. It is also challenging to shape these materials into complex geometries due to their brittle nature. Manufacturing of complex-shaped ceramic parts is possible by electro discharge machining (EDM), if the material has a certain level of electrical conductivity $(>0.3-1 \mathrm{~S} / \mathrm{m})$ [7]. Therefore, it is essential to improve mechanical and electrical properties of ceramic materials, which can be obtained by nanocomposite formation. Porwal et al. [8] have recently reviewed the state of the art for graphene-based ceramic matrix nanocomposites. Although significant improvements of mechanical and electrical properties of monolithic ceramics have been reported with incorporation of graphene-based materials, there are very limited number of 
studies where thermal properties of graphene-based ceramicmatrix nanocomposites have been investigated $[9,10]$.

GPLs generally have higher thickness compared to few-layer (2-5 layers) and multilayer (2-10 layers) graphene due to agglomeration and/or overlapping of individual sheets, but have a Raman spectrum different from that of bulk graphite. GPLs are attractive fillers in nanocomposites since they can be easily produced at a large scale by liquid phase exfoliation and may enable one to develop multifunctional nanocomposites with anisotropic properties for a wide range of applications due to their unique twodimensional geometry, high aspect ratio and stiffness. Due to their relatively high thickness (up to $100 \mathrm{~nm}$ ), GPLs can be preferentially oriented in the matrix during spark plasma sintering (SPS) [9-12] However, the number of studies where anisotropy in graphenebased ceramic matrix nanocomposites was investigated in detail is very limited. Centeno et al. [11] investigated effect of orientation of reduced graphene oxide sheets on mechanical properties of $\mathrm{Al}_{2} \mathrm{O}_{3}$ matrix nanocomposites, but only for one composition (i.e., 0.22 wt.\% graphene-containing $\mathrm{Al}_{2} \mathrm{O}_{3}$ ). Ramirez et al. [12] examined anisotropic electrical conductivity of GPLs-containing $\mathrm{Si}_{3} \mathrm{~N}_{4}$ nanocomposites as a function of orientation of the GPLs. Miranzo et al. [9] investigated anisotropic thermal conductivity of $\mathrm{Si}_{3} \mathrm{~N}_{4}$ ceramics containing GPLs. Rutkowski et al. [10] have very recently prepared $\mathrm{Al}_{2} \mathrm{O}_{3}$-GPLs composites by hot isostatic pressing and SPS, and evaluated the correlation between material anisotropy and thermal conductivity. The authors observed anisotropic microstructure due to preferential orientation of GPLs in perpendicular direction to pressing axis for hot pressed samples, while not much anisotropy was observed for the spark plasma sintered composites. $\mathrm{Al}_{2} \mathrm{O}_{3}$ has been one of the most widely utilized matrix materials; however, the influence of anisotropy on mechanical and functional properties of graphene-based materials $/ \mathrm{Al}_{2} \mathrm{O}_{3}$ nanocomposites has not been clarified in depth, yet. Accordingly, the research objectives of this study were to produce spark plasma sintered $\mathrm{Al}_{2} \mathrm{O}_{3}$ matrix nanocomposites containing GPLs that were prepared by liquid phase exfoliation as a filler, and to develop an understanding about effects of preferential orientation of GPLs in the $\mathrm{Al}_{2} \mathrm{O}_{3}$ matrix on mechanical, electrical and thermal properties of these nanocomposites.

\section{Experimental procedure}

\subsection{GPLs/Al $\mathrm{O}_{2} \mathrm{O}_{3}$ nanocomposite production}

High concentration $(\sim 1.3 \mathrm{mg} / \mathrm{mL})$ graphene-based dispersions were prepared by exfoliation of a high surface area $\left(\sim 175 \mathrm{~m}^{2} / \mathrm{g}\right)$ nano-graphite powder (Surface Enhanced Flake Graphite (Grade 3725), kindly provided by Asbury Carbons, Inc., USA) in isopropyl alcohol (IPA) within 90 min of bath sonication followed by centrifugation at $500 \mathrm{rpm}$ for $45 \mathrm{~min}$. $\alpha-\mathrm{Al}_{2} \mathrm{O}_{3}$ powder (TM-DAR, Taimei Chemicals Co., Japan-99.99\% purity and $\sim 0.1 \mu \mathrm{m}$ average particle size) was dispersed separately in IPA by magnetic stirring for $\sim 1 \mathrm{~h}$ in combination with bath sonication for $\sim 5 \mathrm{~min}$ in every $15 \mathrm{~min}$. The graphene-based dispersion was then incorporated into the $\mathrm{Al}_{2} \mathrm{O}_{3}$ suspension during magnetic stirring in required amounts as to provide 3, 5, 7, 9, 10 and 15 vol.\% GPLs and stirred for $\sim 45 \mathrm{~min}$. The resulting GPLs/ $/ \mathrm{Al}_{2} \mathrm{O}_{3}$ mixtures were ball-milled in IPA at $200 \mathrm{rpm}$ for $3 \mathrm{~h}$ using yttria-stabilized $\mathrm{ZrO}_{2}$ balls. The milled slurry was dried by rotary evaporator and then ground in an agate mortar. Well dispersed GPLs $/ \mathrm{Al}_{2} \mathrm{O}_{3}$ powder was then loaded into a $14 \mathrm{~mm}$ inner diameter graphite die and sintered by spark plasma sintering (SPS, FCT Systeme $\mathrm{GmbH}-$ Anlagenbau, Germany) at $1250-1600^{\circ} \mathrm{C}$ (depending on the graphene content) for 5 min under a uniaxial pressure of $50 \mathrm{MPa}$. The dimensions of the sintered samples were ca. $14 \mathrm{~mm}$ in diameter and $8 \mathrm{~mm}$ in thickness. SPS method enables rapid heating rates and applying pressure simultaneously; therefore, it limits thermally induced structural damage to the graphene by avoiding long processing times at high temperatures [13]. As a result of the applied pressure during SPS, GPLs are preferentially oriented in the matrix with their basal planes perpendicular to the SPS pressing axis, as shown in Fig. 1. The direction parallel to the SPS pressing axis will be referred to as through-thickness and the direction perpendicular to the SPS pressing axis will be referred to as in-plane direction, from now on. Mechanical, thermal and electrical characterizations of the nanocomposites were performed by taking this anisotropy into consideration. Samples with ca. $8 \mathrm{~mm} \times 8 \mathrm{~mm} \times 1-2 \mathrm{~mm}$ were cut along both the in-plane and through-thickness directions for further characterization.

Density of the nanocomposites was measured by Archimedes method with water immersion. In order to determine their relative density, the theoretical density of the nanocomposites was calculated by the volume-based rule of mixtures assuming densities of $3.96 \mathrm{~g} / \mathrm{cm}^{3}$ and $2.2 \mathrm{~g} / \mathrm{cm}^{3}$ for $\mathrm{Al}_{2} \mathrm{O}_{3}$ and GPLs, respectively. The microstructure of the samples was characterized by field emission gun-scanning electron microscope (FEG-SEM, Supra 50 VP). MicroRaman analyses of the initial GPLs, the as-prepared 10 vol.\% GPLs containing $\mathrm{Al}_{2} \mathrm{O}_{3}$ powder and of the 10 vol.\% $\mathrm{GPLs} / \mathrm{Al}_{2} \mathrm{O}_{3}$ nanocomposites (on both through-thickness and in-plane directions) were performed on a Renishaw Invia spectrometer using $532 \mathrm{~nm}$ laser excitation and $100 \times$ objective lens. The laser power was kept below $1 \mathrm{~mW}$ in order to prevent sample damage. 50 spectra were recorded (each one at a different location) for these samples to create statistical histogram of the $I_{\mathrm{D}} / I_{\mathrm{G}}$ ratio.

\subsection{Mechanical characterization}

Vickers hardness tests were performed by applying a force of $2 \mathrm{~kg}$ on the polished sample surfaces. Hardness and fracture toughness values of the monolithic $\mathrm{Al}_{2} \mathrm{O}_{3}$ and the nanocomposites were determined from Vickers indentations (average of three indentations) and the corresponding crack-length measurements using the equations developed by Evans and Charles [14].

\subsection{Electrical characterization}

Electrical measurements were also performed along both inplane and through-thickness directions. The resistance of the samples was first measured by Signatone semi-automatic probe station connected to Keithley 4200 semiconductor characterization system. Au-Pd coating was applied to the surfaces of interest by sputtering. Monolithic $\mathrm{Al}_{2} \mathrm{O}_{3}$ and nanocomposites with 3,5 and 7 vol.\% GPLs exhibited high resistance, while nanocomposites with higher GPLs contents showed conductive behavior. In order to eliminate the possible effect of sample thickness on the orientation dependent conductivity measurements, cubic samples $(\sim 5 \mathrm{~mm} \times 5 \mathrm{~mm} \times 5 \mathrm{~mm})$ were cut from the sintered nanocomposites with 9,10 and 15 vol.\% GPLs. The corresponding surfaces of the

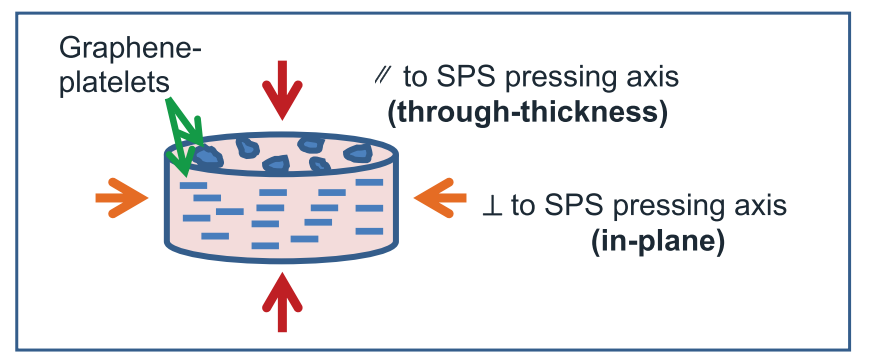

Fig. 1. Schematic representation of orientation of GPLs in the matrix with the help of applied pressure during SPS process. 

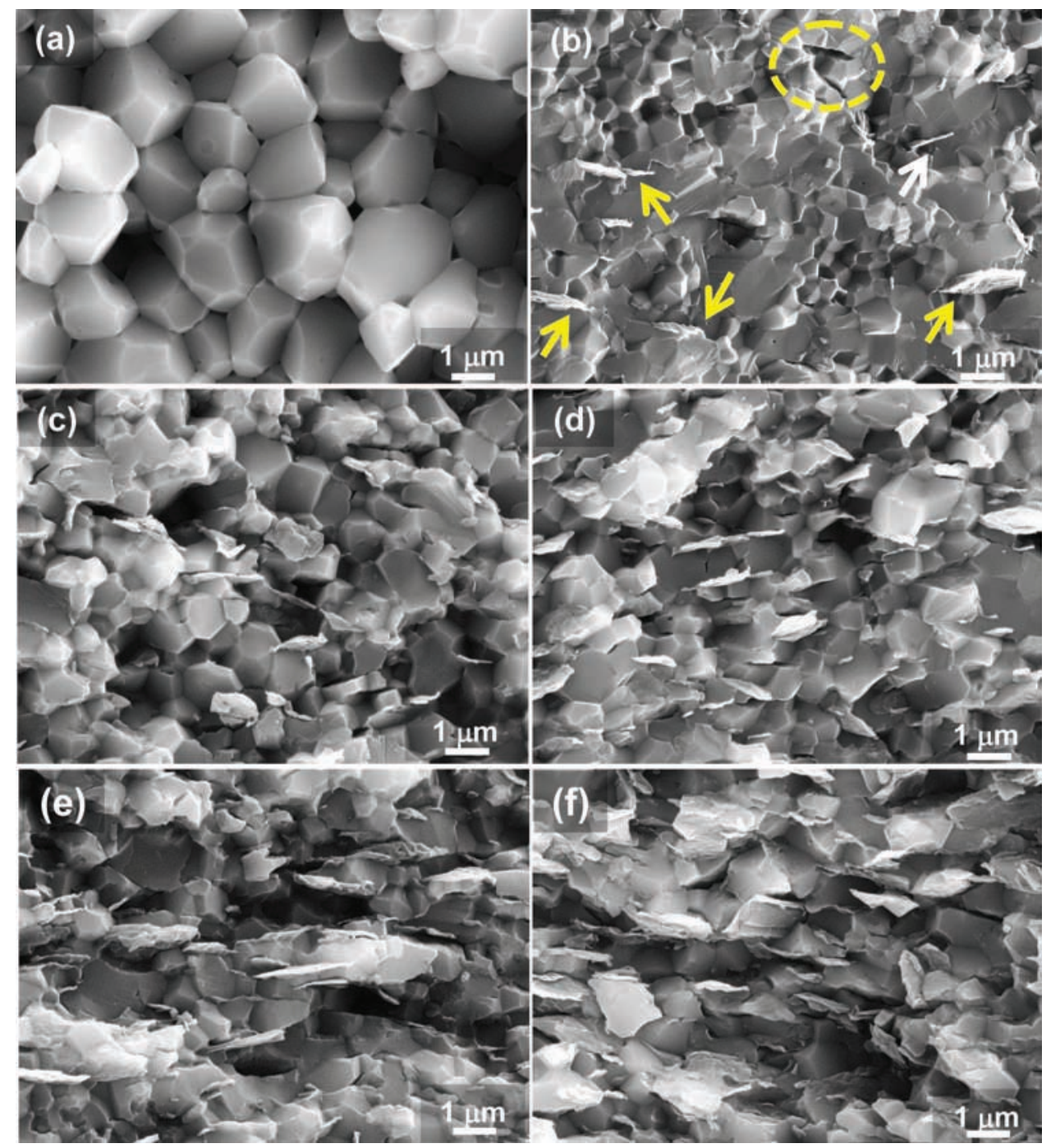

Fig. 2. FEG-SEM micrographs of fracture surfaces of (a) monolithic $\mathrm{Al}_{2} \mathrm{O}_{3}$ and of nanocomposites with GPLs contents of (b) 3 vol.\%, (c) 5 vol.\%, (d) 7 vol.\%, (e) 10 vol.\% and (f) 15 vol.\%. Arrows indicate the aligned protruded and pulled-out GPLs; dashed circle shows the pulled-out GPLs.

cubic samples were coated with Au-Pd before each measurement. The resistance values were measured by Agilent 4294 Precision Impedance Analyzer in through-thickness and in-plane directions and the corresponding conductivity values were then calculated.

\subsection{Thermal characterization}

In-plane and through-thickness thermal diffusivity measurements were carried out from room temperature up to $600^{\circ} \mathrm{C}$ at intervals of $\sim 100^{\circ} \mathrm{C}$ in $\mathrm{N}_{2}$ atmosphere by laser flash method using Netzsch LFA 457 Microflash (USA) equipment. Three shots were recorded per temperature for each sample and the data were averaged. Specific heat $\left(C_{p}\right)$ measurements of the monolithic $\mathrm{Al}_{2} \mathrm{O}_{3}$ and the nanocomposites with 3, 7, 10 and 15 vol.\% GPLs contents were carried out by a differential scanning calorimeter (Netzsch STA $449 \mathrm{~F} 3$, USA) in $42-700^{\circ} \mathrm{C}$ temperature range in $\mathrm{N}_{2}$ atmosphere using a sapphire crystal as a reference. The $C_{p}$ values at room temperature and of the 5 and $15 \mathrm{vol} . \% \mathrm{GPLs} / \mathrm{Al}_{2} \mathrm{O}_{3}$ samples were determined by extrapolation and interpolation of the measured data. The corresponding thermal conductivity $(k)$ values were calculated by using the following equation [15]:

$k=\alpha \times \rho \times C_{p}$ where $\alpha$ and $\rho$ represent the thermal diffusivity and density, respectively.

\section{Results and discussion}

\subsection{Microstructure development}

The exfoliated nano-graphite powder used in the present study is mostly composed of few-layer ( $<5$ layers) graphene sheets with a lateral size of $<1 \mu \mathrm{m}(\sim 400 \mathrm{~nm}$ in average diameter of equivalent spherical particle as determined by dynamic light scattering analysis) as confirmed by high resolution TEM and Raman analyses. However, the individual few-layer graphene sheets are usually folded, scrolled and entangled each other during processing, forming the so-called GPLs in this study.

Each nanocomposite was sintered at a specific temperature depending on their GPLs content to ensure that all the nanocomposites exhibit as high densification as possible. As a result, the monolithic $\mathrm{Al}_{2} \mathrm{O}_{3}$ and the nanocomposites were highly densified with relative densities of $\geq 98.5 \%$. Table 1 shows sintering temperatures of the nanocomposites depending on the GPLs content and the resultant grain size of the nanocomposites. Sintering of each sample at their optimum sintering temperature enables one 
Table 1

Sintering temperature, relative density and mean grain size for the monolithic $\mathrm{Al}_{2} \mathrm{O}_{3}$ and the nanocomposites.

\begin{tabular}{|c|c|c|c|}
\hline GPLs content (vol.\%) & Sintering temperature $\left({ }^{\circ} \mathrm{C}\right)$ & Relative density (\%TD) & Mean grain size $(\mu \mathrm{m})$ \\
\hline 0 & 1250 & 100 & 2.39 \\
\hline 3 & 1350 & 99.6 & Bimodal $(0.70,1.40)$ \\
\hline 5 & 1400 & 99.4 & 1.27 \\
\hline 7 & 1450 & 98.7 & 1.31 \\
\hline 9 & 1500 & 99.2 & 1.31 \\
\hline 10 & 1525 & 98.7 & 1.36 \\
\hline 15 & 1600 & 98.5 & 1.33 \\
\hline
\end{tabular}

Table 2

Mechanical properties of GPLs/alumina nanocomposites.

\begin{tabular}{|c|c|c|c|}
\hline GPLs content (vol.\%) & Hardness (GPa) & $K_{\mathrm{IC}}$ (through-thickness) $\left(\mathrm{MPa} \mathrm{m}^{1 / 2}\right)$ & $K_{\mathrm{IC}}$ (in-plane) $\left(\mathrm{MPa} \mathrm{m}^{1 / 2}\right)$ \\
\hline 0 & $18.4 \pm 0.86$ & $2.9 \pm 0.06$ & $3.0 \pm 0.14$ \\
\hline 3 & $16.2 \pm 0.11$ & $2.4 \pm 0.03$ & $3.8 \pm 0.13$ \\
\hline 5 & $15.1 \pm 0.27$ & $2.6 \pm 0.06$ & $3.6 \pm 0.15$ \\
\hline 7 & $13.1 \pm 0.33$ & $2.8 \pm 0.02$ & $3.0 \pm 0.05$ \\
\hline 9 & $11.8 \pm 0.12$ & $3.0 \pm 0.11$ & $3.1 \pm 0.06$ \\
\hline 10 & $11.3 \pm 0.18$ & $3.2 \pm 0.10$ & $2.8 \pm 0.05$ \\
\hline 15 & $9.8 \pm 0.19$ & $3.2 \pm 0.06$ & $2.6 \pm 0.05$ \\
\hline
\end{tabular}

to investigate the effect of GPLs on the mechanical properties more clearly by eliminating the effect of grain size on these properties. As could be expected, the sintering temperature increased with the GPLs content.

Fig. 2 shows FEG-SEM micrographs of the fracture surfaces of sintered monolithic $\mathrm{Al}_{2} \mathrm{O}_{3}$ and nanocomposites. The monolithic $\mathrm{Al}_{2} \mathrm{O}_{3}$ is composed of equiaxed-shaped faceted grains with $\sim 2.4 \mu \mathrm{m}$ in size in average (determined by Image software) (Fig. 2a). Addition of GPLs inhibited grain growth of $\mathrm{Al}_{2} \mathrm{O}_{3}$ resulting in a finer microstructure (Table 1 and Fig. 2). This could be attributed to the pinning effect of uniformly distributed GPLs which hinders movement of grain boundaries. Except for the nanocomposite with 3 vol.\% GPLs content, the fracture surfaces of the sintered nanocomposites revealed mostly uniform microstructures indicating the homogeneous distribution of GPLs throughout the matrix (Fig. 2). It can be clearly seen from these micrographs that some of the GPLs are agglomerated and overlapped forming flakes with $\sim 50 \mathrm{~nm}$ in thickness, while the thinner ones are located around the matrix grains and cannot be easily observed. The thick GPLs are aligned in the matrix with their basal planes perpendicular to the SPS pressing axis, leading to an anisotropic microstructure (Fig. 2b-f); consequently, orientation dependent fracture toughness values were observed. 3 vol.\% GPLs containing nanocomposite exhibited a bimodal microstructure with some very fine $(\sim 0.7 \mu \mathrm{m}$ in diameter), faceted and equiaxed matrix grains, as well as relatively larger grains ( $\sim 1.4 \mu \mathrm{m}$ in average) (Fig. $2 \mathrm{~b}$ ). This may indicate that 3 vol.\% GPLs content is not sufficient to be distributed around most of the $\mathrm{Al}_{2} \mathrm{O}_{3}$ grains in the matrix; therefore, different grain growth rates were observed in the microstructure. Higher GPLs loadings resulted in much more uniform microstructures.

\subsection{Mechanical properties}

The fracture surface of monolithic $\mathrm{Al}_{2} \mathrm{O}_{3}$ revealed an intergranular fracture mode, while the GPLs/ $\mathrm{Al}_{2} \mathrm{O}_{3}$ nanocomposites exhibited a combination of transgranular and intergranular fractures (Fig. 2). The trend of the $\mathrm{Al}_{2} \mathrm{O}_{3}$ grains to fracture transgranularly in the nanocomposites indicates the improved interfacial strength, relative to the grain strength. The fracture mode and the mechanical properties of ceramic nanocomposites strongly depend on the strength of grain boundaries. The strong boundary may force the cracks to deflect into the matrix grain, resulting in a transgranular fracture [16]. Fan et al. [17] reported that the phenomena of transgranular fracture increases in milled expanded graphite containing

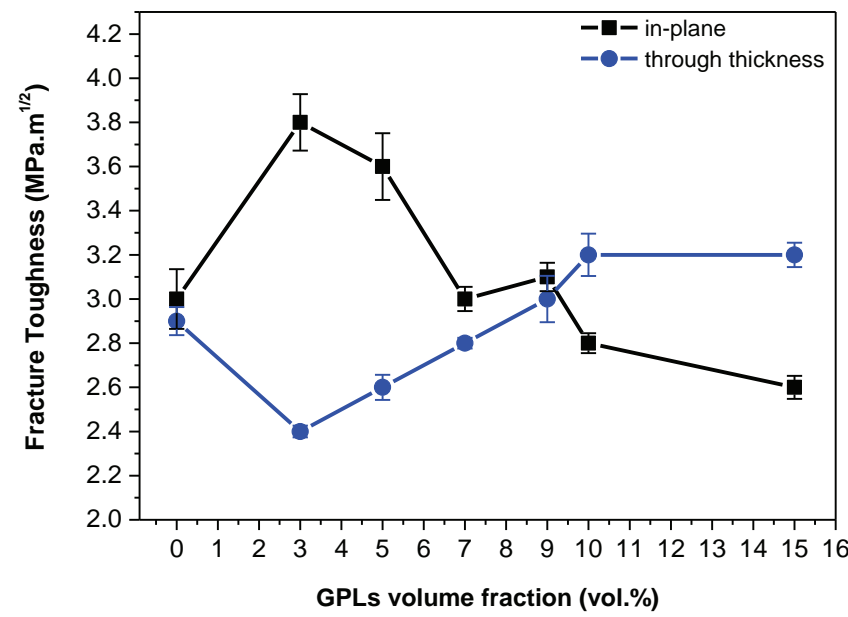

Fig. 3. Through-thickness and in-plane fracture toughness values of $\mathrm{GPLs} / \mathrm{Al}_{2} \mathrm{O}_{3}$ nanocomposites as a function of GPLs content.

$\mathrm{Al}_{2} \mathrm{O}_{3}$ nanocomposites compared to monolithic $\mathrm{Al}_{2} \mathrm{O}_{3}$, suggesting the high strength of the graphene-based material, as in agreement with the present study. On the other hand, Wang et al. [18] reported that their reduced graphene oxide-based $\mathrm{Al}_{2} \mathrm{O}_{3}$ nanocomposite exhibited predominantly intergranular fracture mode. The authors explained this phenomenon by the existence of residual stress at the $\mathrm{Al}_{2} \mathrm{O}_{3}$ grain boundaries caused by thermal expansion mismatch which may weaken the interface boundaries. The differences in fracture modes observed in various studies can be attributed to the differences in graphene-based materials (in terms of thickness, aspect ratio, quality, etc.) and to the differences in nanocomposite production techniques, as also highlighted by Dusza et al. [19].

Table 2 shows the mechanical properties of the monolithic $\mathrm{Al}_{2} \mathrm{O}_{3}$ and the GPLs $/ \mathrm{Al}_{2} \mathrm{O}_{3}$ nanocomposites. It was observed that hardness values decreased with GPLs content, although the nanocomposites have a much finer microstructure in comparison to the monolithic $\mathrm{Al}_{2} \mathrm{O}_{3}$. This can be explained by sliding or cleavage of GPLs under the in-plane and out-of plane stresses, as suggested by Fan et al. [20].

Fracture toughness of the monolithic $\mathrm{Al}_{2} \mathrm{O}_{3}$ and the nanocomposites as a function of GPLs content is plotted along both through-thickness and in-plane directions in Fig. 3. Preferential orientation of GPLs throughout the matrix resulted in anisotropy in the 

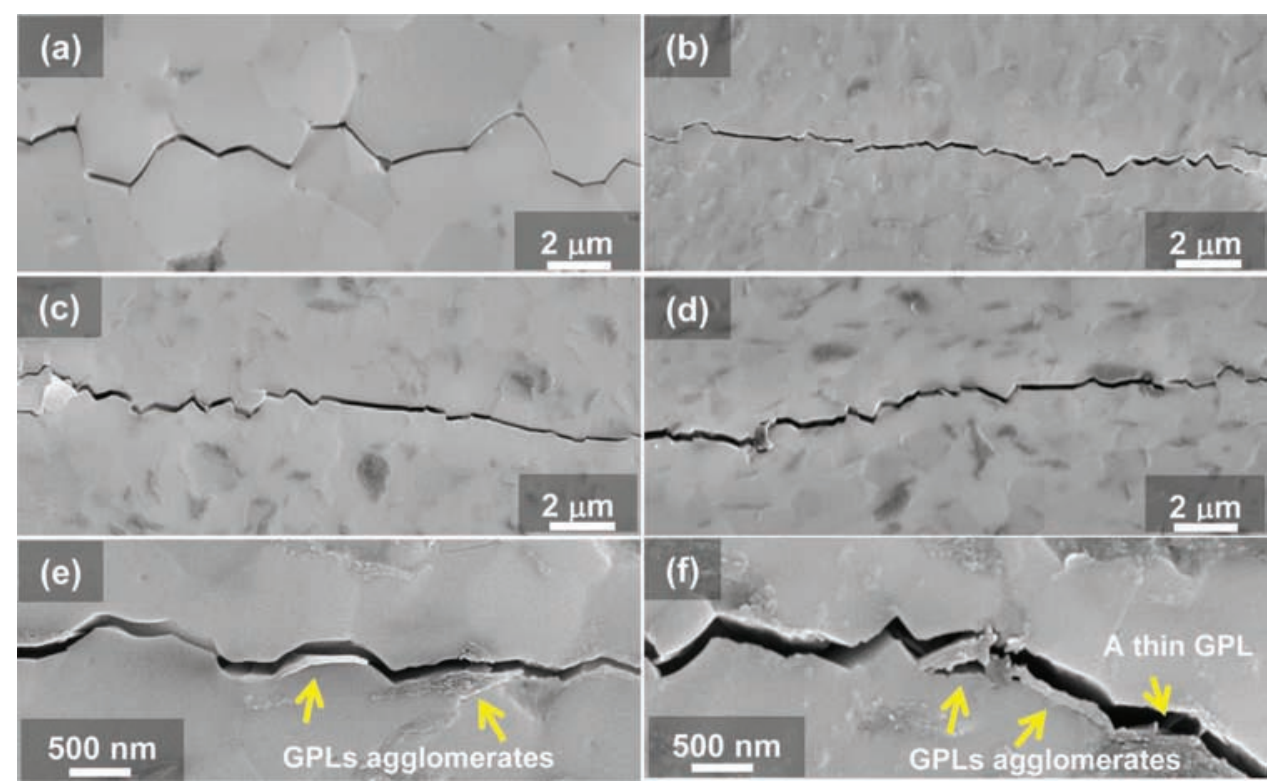

Fig. 4. FEG-SEM micrographs of in-plane crack paths (created by indentation) of (a) monolithic $\mathrm{Al}_{2} \mathrm{O}_{3}$ and of $\mathrm{GPLS} / \mathrm{Al}_{2} \mathrm{O}_{3}$ nanocomposites with (b) 3 vol.\%, (c) 5 vol.\%, (d) 7 vol.\% GPLs, (e) 10 vol.\%, and (f) 15 vol.\% GPLs. The magnification of (e) and (f) is higher than that of (a)-(d).

fracture toughness values. Fracture toughness of monolithic $\mathrm{Al}_{2} \mathrm{O}_{3}$ was almost the same in the in-plane and through-thickness directions (3.0 and $2.9 \mathrm{MPa} \mathrm{m}^{1 / 2}$, respectively). It increased by $\sim 26.7 \%$ in the in-plane direction and decreased by $\sim 17.2 \%$ in through thickness direction with the addition of 3 vol.\% GPLs into the monolithic $\mathrm{Al}_{2} \mathrm{O}_{3}$ (Fig. 3). The FEG-SEM micrograph of the fracture surface of this nanocomposite revealed the protruded and pulled-out thick GPLs, which are aligned mostly through the inplane direction (Fig. 2). The change of the fracture mode from intergranular to transgranular with the introduction of GPLs into the monolithic $\mathrm{Al}_{2} \mathrm{O}_{3}$ is a clear indication of improved interfacial strength; however, it is clear that this bonding is weak enough to allow de-bonding at the GPLs- $\mathrm{Al}_{2} \mathrm{O}_{3}$ interface in the in-plane direction. Delamination of the GPLs themselves may also occur. As a result, energy that would normally cause crack propagation is partially expended by de-bonding and shear, resulting in an increase in fracture toughness [21]. Accordingly, pull-out was supposed to be the main toughening mechanism for the 3 vol.\% GPLs containing $\mathrm{Al}_{2} \mathrm{O}_{3}$ nanocomposite in the in-plane direction. Further increase in GPLs content started to decrease the in-plane fracture toughness (Fig. 3, Table 2). The highest GPLs loading (15 vol.\%) resulted in a reduction in the fracture toughness by $\sim 13.3 \%$ and $\sim 31.6 \%$ compared to the monolithic $\mathrm{Al}_{2} \mathrm{O}_{3}$ and the 3 vol.\% GPLs containing nanocomposite, respectively. The decrease in the fracture toughness could be attributed to weakening of the interface after a certain amount of GPLs loadings ( $>3$ vol.\%).

Fig. $4 a-d$ show in-plane crack paths originating from the Vickers indentations on the monolithic $\mathrm{Al}_{2} \mathrm{O}_{3}$ and the nanocomposites with 3, 5 and 7 vol.\% GPLs contents. The crack paths of the nanocomposites revealed both straight and tortuous regions indicating that the fracture is a mixture of intergranular and transgranular modes, as in agreement with the fracture surfaces. GPLs showed a higher tendency to agglomerate and to overlap at higher loadings. As a result of this agglomeration/overlapping, the amount of large pores between the matrix grains and the thick GPLs increased resulting in weakening of the interfacial bonding in the in-plane direction (Fig. 4e and f). This is in agreement with Liu et al. [22] who reported that the large pores are thought to be the origin of the fractures and reduce the strength of ceramic composites. Dusza et al. [19] prepared $\mathrm{Si}_{3} \mathrm{~N}_{4}$ matrix nanocomposites using various graphene-based materials with different geometry, length/width and thickness. Similarly, they observed that the GPLs with larger lateral size and higher thickness, and overlapped GPLs are usually connected with porosity, which may result in a weak adhesion bond of GPLs/matrix and lower energy dissipation during pull-out [19].

The decrease in the through-thickness fracture toughness with 3 vol.\% GPLs addition could be attributed to the GPLs- $\mathrm{Al}_{2} \mathrm{O}_{3}$ interface which might be too strong in that direction; therefore, the possible pull-out or bridging mechanisms are prevented and the crack is forced to pass through the GPLs. Further increase in GPLs amount started to increase the fracture toughness in through-thickness direction, and the fracture toughness of the nanocomposites got higher than that of the monolithic $\mathrm{Al}_{2} \mathrm{O}_{3}$ at GPLs loadings of $\geq 9$ vol.\% (Fig. 3 ). Fig. 5 shows the FEG-SEM micrographs of the through-thickness crack paths originating from the Vickers indentations on the monolithic $\mathrm{Al}_{2} \mathrm{O}_{3}$ and the nanocomposites with 3, 5, 7, 10 and 15 vol.\% GPLs contents. The crack path of the $5 \mathrm{vol}$ \% GPLs/ $/ \mathrm{Al}_{2} \mathrm{O}_{3}$ nanocomposite, which exhibited a slightly higher fracture toughness than that of the 3 vol.\% $\mathrm{GPLs} / \mathrm{Al}_{2} \mathrm{O}_{3}$ nanocomposite, but that is still lower than that of the monolithic alumina, showed a damaged GPLs induced by crack penetration through it (Fig. 5c). Crack deflection and crack bridging were observed as the main toughening mechanisms in throughthickness direction especially at relatively low GPLs loadings ( $\sim 5-7$ vol.\%) (Fig. $5 \mathrm{c}$ and d). Increasing GPLs content to $\geq 9$ vol.\% led to a much more tortuous and narrower crack path (Fig. 5e-f). Crack branching appeared for the 15 vol.\% GPLs containing nanocomposite as a dominant toughening mechanism (Fig. 5f), resulting in $\sim 10 \%$ and $\sim 33 \%$ increase in fracture toughness with respect to the monolithic $\mathrm{Al}_{2} \mathrm{O}_{3}$ and the 3 vol.\% GPLs containing nanocomposite, respectively (Fig. 3 , Table 2 ). These results revealed that the mechanical properties of the GPLs/ $\mathrm{Al}_{2} \mathrm{O}_{3}$ nanocomposites are strongly affected by the orientation of the GPLs throughout the matrix.

In contrast to relatively high improvements of fracture toughness of ceramic materials with graphene-based material reinforcing, such as $75 \%$ and $135 \%$ improvements as reported by Kim et al. [6] and Walker et al. [13], respectively; lower increment has been achieved in the present study. The relatively low fracture toughness values could arise from the tendency of the GPLs to 

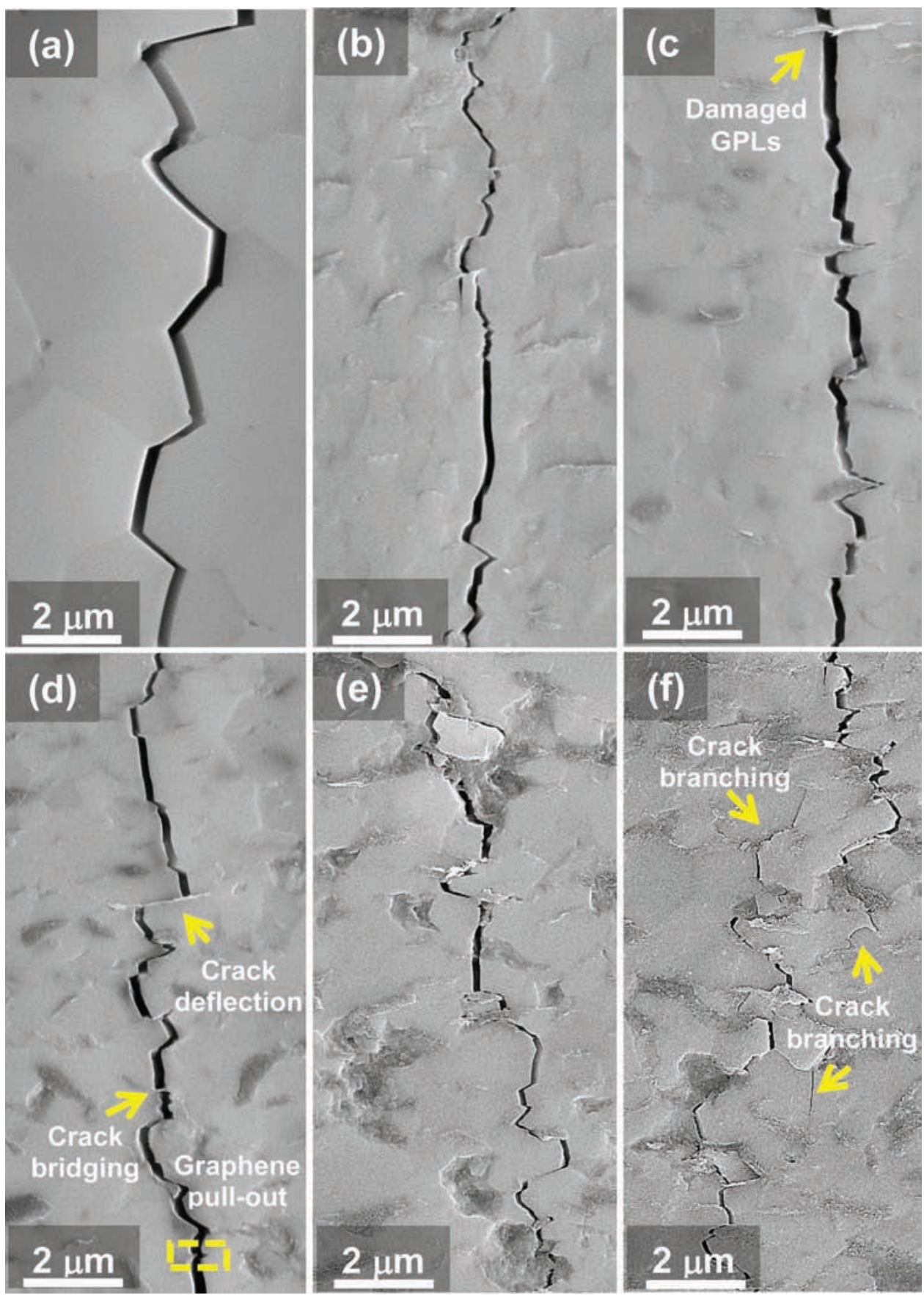

Fig. 5. FEG-SEM micrographs of through-thickness crack paths (created by indentation) of (a) monolithic $\mathrm{Al}_{2} \mathrm{O}_{3}$ and of $\mathrm{GPLs} / \mathrm{Al}_{2} \mathrm{O}_{3}$ nanocomposites with (b) 3 vol.\%, (c) 5 vol.\%, (d) 7 vol.\%, (e) 10 vol.\% and (f) 15 vol.\% GPLs.

agglomerate and to overlap especially at relatively high loadings, and from lower aspect ratio of the GPLs used in the present study. The extent of the final toughening strongly depends on the aspect ratio of the graphene-based material and high aspect ratio platelets are generally found to be more beneficial to the mechanical properties of a composite [4]. The intrinsic mechanical properties of the graphene-based fillers also play an important role in their reinforcement efficiency. Kim et al. [6] produced graphene-based alumina nanocomposites by pressureless sintering using different graphene-based materials (chemically exfoliated graphene, graphene oxide and reduced-graphene oxide) and compared the mechanical properties of these nanocomposites. They reported that the ultra-thin $(2-5 \mathrm{~nm})$ chemically exfoliated graphene (0.5 vol.\%), which has the lowest defects, provided the greatest improvement $(\sim 75 \%)$ in fracture toughness compared to monolithic $\mathrm{Al}_{2} \mathrm{O}_{3}$ [6]. Graphene oxide and reduced-graphene oxide showed little or less enhancement of fracture toughness (by $14 \%$ and $48 \%$, respectively) due to degraded mechanical strength of the reduced-graphene oxide and the structural defects of the graphene oxide composites [6].

The defects may originate intrinsically from the initial GPLs or can be formed during processing of the nanocomposites. Raman spectroscopy was used to evaluate the quality of the GPLs in the nanocomposites before and after SPS process in order to compare with the initial GPLs. 


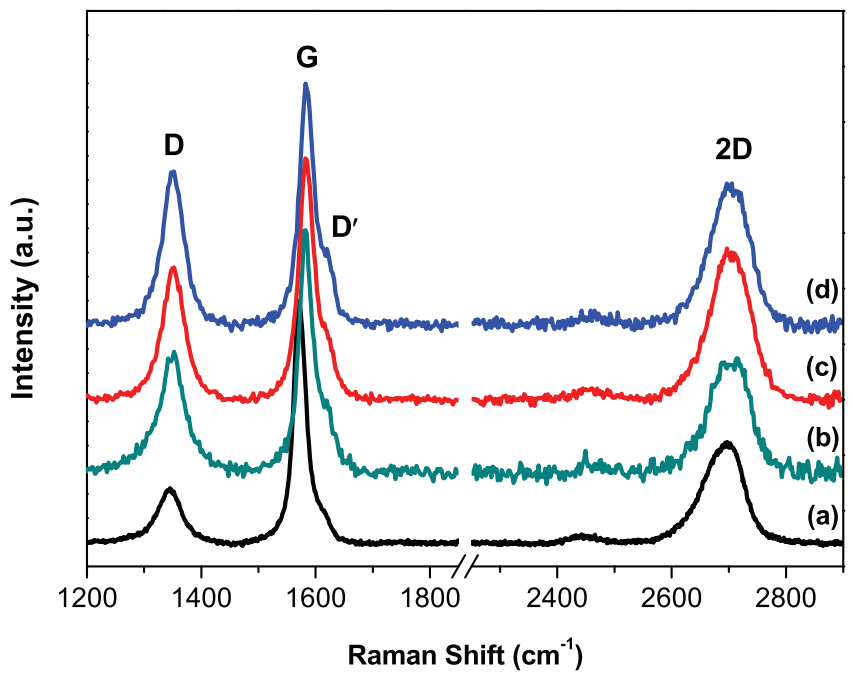

Fig. 6. Raman spectra of the (a) Initial GPLs, (b) $10 \mathrm{vol} \% \mathrm{GPLs} / \mathrm{Al}_{2} \mathrm{O}_{3}$ powder (before SPS), (c) 10 vol.\% GPLs $/ \mathrm{Al}_{2} \mathrm{O}_{3}$ nanocomposite in through-thickness direction, and (d) 10 vol.\% GPLs $/ \mathrm{Al}_{2} \mathrm{O}_{3}$ nanocomposite in in-plane direction. The spectra are normalized to the G-band.

\subsection{Raman measurements}

Fig. 6 shows Raman spectra of the initial GPLs, as-prepared 10 vol.\% GPLs-containing $\mathrm{Al}_{2} \mathrm{O}_{3}$ powder (before SPS) and of the 10 vol.\% GPLs $/ \mathrm{Al}_{2} \mathrm{O}_{3}$ nanocomposite both in through-thickness and in-plane directions, and Table 3 gives a summary of the measured
Raman characteristics. Each spectrum shows a G-band, which is related to the stretching of the $\mathrm{C}=\mathrm{C}$ bond in graphitic materials and is common to all $\mathrm{sp}^{2}$-bonded carbon systems, the so-called disorder/defect-induced $\mathrm{D}$ and $\mathrm{D}^{\prime}$-bands, and the second order 2Dband which is attributed to a second-order process related to a phonon near the $\mathrm{K}$ point in graphene and activated by double resonance process [23] (Fig. 6). The shape of the 2D-band of all the samples is distinctly different from that of graphite which consists of two peaks [23]. This indicates the presence of few-layer (2-5 layers) and/or multi-layer (5-10 layers) graphene flakes both in the initial graphene-based material and in the nanocomposites. It was also observed that the G-band of the as-prepared GPLs/ $/ \mathrm{Al}_{2} \mathrm{O}_{3}$ powder and the sintered GPLs/ $/ \mathrm{Al}_{2} \mathrm{O}_{3}$ nanocomposite was blue-shifted by $\sim 7 \mathrm{~cm}^{-1}$ and $-10 \mathrm{~cm}^{-1}$, respectively, accompanied by a bandwidth broadening in comparison to that of initial GPLs (Fig. 6, Table 3). The blue-shift and broadening of the G-band frequency and width, respectively, observed in the nanocomposites can be attributed to charge doping induced by the $\mathrm{Al}_{2} \mathrm{O}_{3}$ matrix $[24,25]$. It has been shown that the G-band position upshifts for both electron and hole doping [25].

The Raman spectra of the as-prepared 10 vol.\% $\mathrm{GPLs} / \mathrm{Al}_{2} \mathrm{O}_{3}$ powder and of the sintered 10 vol.\% GPLs/ $/ \mathrm{Al}_{2} \mathrm{O}_{3}$ nanocomposite revealed an increase in the intensity of the $\mathrm{D}^{\prime}$-band $\left(\right.$ at $\sim 1620 \mathrm{~cm}^{-1}$ ) compared to that of the initial GPLs indicating an increment in the amount of defects (Fig. 6). The intensity ratio of the D-band to $\mathrm{G}$-band $\left(I_{\mathrm{D}} / I_{\mathrm{G}}\right)$ is generally used to characterize defect content quantitatively [23]. Fig. 7 shows statistical histograms of the $I_{\mathrm{D}} / I_{\mathrm{G}}$ ratio for the initial GPLs, 10 vol.\% GPLs containing $\mathrm{Al}_{2} \mathrm{O}_{3}$ powder before sintering and the sintered 10 vol.\% GPLs containing $\mathrm{Al}_{2} \mathrm{O}_{3}$
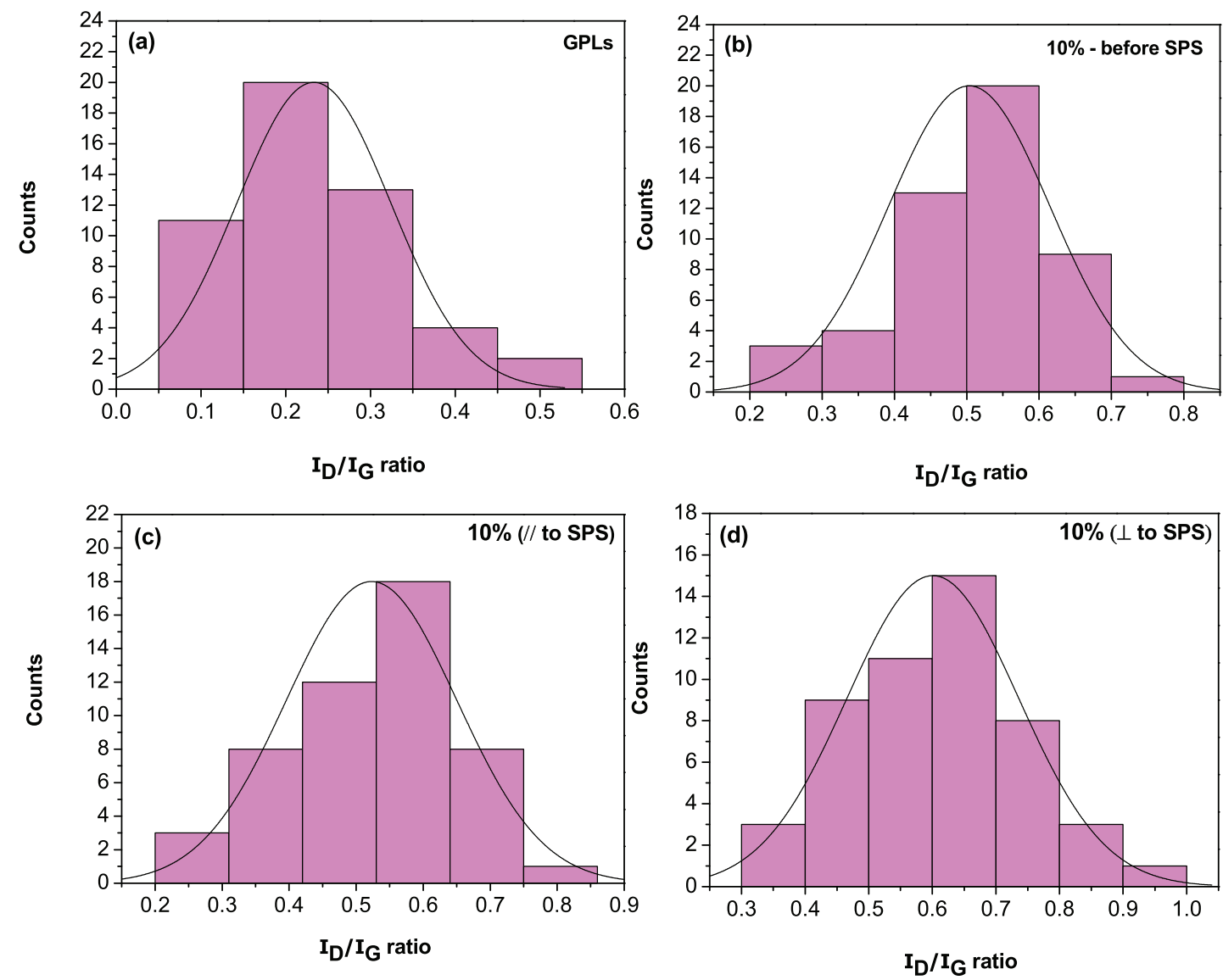

Fig. 7. Statistical histogram of the D-band intensity to G-band intensity ratios ( $\mathrm{I}_{\mathrm{D}} / \mathrm{I}_{\mathrm{G}}$ ) derived from 50 Raman spectra. (a) Initial GPLs, (b) 10 vol.\% GPLs/Al $\mathrm{O}_{3}$ powder (before $\mathrm{SPS}$ ), (c) 10 vol.\% GPLs/ $/ \mathrm{Al}_{2} \mathrm{O}_{3}$ nanocomposite in through-thickness direction, and (d) 10 vol.\% $\mathrm{GPLs} / \mathrm{Al}_{2} \mathrm{O}_{3}$ nanocomposite in in-plane direction. The distribution curves indicate the mean of the data. 
Table 3

Raman features of the GPLs, 10 vol.\% GPLs containing $\mathrm{Al}_{2} \mathrm{O}_{3}$ powder and of the sintered 10 vol.\% GPLs/ $\mathrm{Al}_{2} \mathrm{O}_{3}$ nanocomposite recorded for both in-plane ( $\perp$ ) and throughthickness (//) directions. The data are the average of 50 spectra.

\begin{tabular}{llll}
\hline & GPLs (initial) & $10 \% \mathrm{GPLs} / \mathrm{Al}_{2} \mathrm{O}_{3}$ (before SPS) & $10 \% \mathrm{GPLs}_{\mathrm{Al}} \mathrm{O}_{3}(/ /)$ \\
\hline G-band $\omega\left(\mathrm{cm}^{-1}\right)$ & 1574 & 1581 & 1584 \\
G-bandFWHM $\left(\mathrm{cm}^{-1}\right)$ & 25 & 28 & 1584 \\
$I_{\mathrm{D}} / I_{\mathrm{G}}$ & $0.24 \pm 0.01$ & $0.50 \pm 0.02$ & 30 \\
\hline
\end{tabular}

nanocomposite both in through-thickness and in-plane directions. While the $I_{\mathrm{D}} / I_{\mathrm{G}}$ ratio of the initial GPLs ranged from $\sim 0.05$ to $\sim 0.55$ with a mean value of $\sim 0.24$, this ratio varied from $\sim 0.2$ to $\sim 0.8$ with a mean value of $\sim 0.5$ for the $10 \mathrm{vol} . \% \mathrm{GPLs} / \mathrm{Al}_{2} \mathrm{O}_{3}$ powder (Fig. $7 \mathrm{a}$ and b). The significant increase in the $I_{\mathrm{D}} / I_{\mathrm{G}}$ ratio indicates that the powder preparation process (i.e., ball milling) introduced some defects into GPLs. Sintering of this powder did not alter the $I_{\mathrm{D}} / I_{\mathrm{G}}$ ratio much (a mean value of 0.52 in through-thickness direction) revealing that the SPS process does not damage GPLs, as in agreement with Miranzo et al. [9]. However, the $I_{\mathrm{D}} / I_{\mathrm{G}}$ ratio of the nanocomposite was slightly higher for the in-plane direction, which ranged from $\sim 0.3$ to $\sim 1$ with a mean value of $\sim 0.6$, than that of the throughthickness direction (Fig. $7 \mathrm{c}$ and d). Higher $I_{\mathrm{D}} / I_{\mathrm{G}}$ ratio in the in-plane direction arises from the presence of more flake edges in that direction, confirming the anisotropic structure of the nanocomposites. Centeno et al. [11] observed a similar orientation influence on the Raman spectra of their reduced graphene oxide $/ \mathrm{Al}_{2} \mathrm{O}_{3}$ nanocomposites; however, the $I_{\mathrm{D}} / I_{\mathrm{G}}$ ratios of their nanocomposites are much higher ( $\sim 1.13$ for the in-plane direction and $\sim 0.83$ for the throughthickness direction). It should be also noted that no correlation was observed between the graphene orientation in the nanocomposites and Raman signal intensity, in contrast to the observations of Centeno et al. [11].

\subsection{Electrical properties}

The electrical conductivity of composites, which are formed by addition of a conductive filler into an insulating material, follows a power-law near the percolation threshold $[26,27]$ and can be expressed by the classical percolation theory as:

$\sigma_{\mathrm{el}(\mathrm{c})}=\sigma_{0}\left(\varphi-\varphi_{\mathrm{c}}\right)^{t_{\mathrm{c}}}$ for $\varphi>\varphi_{\mathrm{c}}$

where $\sigma_{\mathrm{el}(\mathrm{c})}$ is the conductivity of the composite, $\sigma_{0}$ is a parameter depending on the electrical conductivity of the filler material, $t_{\mathrm{c}}$ is the critical exponent, and $\varphi$ and $\varphi_{\mathrm{c}}$ are the volume fraction and the critical volume fraction (percolation threshold) of the filler material, respectively. The critical exponent is universal, with most widely accepted values of 1.3 and 1.94 for two-dimensional and three-dimensional percolating systems, respectively [27]. It depends only on the type of percolation model and on the dimensionality of the system [28]. $\varphi_{c}$ depends on the filler geometry, dispersion, and nature of the conduction between particles. Therefore, finding values of $t_{\mathrm{c}}$ and $\varphi_{\mathrm{c}}$ enables one to understand the nature of particle dispersions and percolation processes [29]. These values can be determined by fitting of the experimental data to the percolation model.

Fig. 8 shows the electrical conductivity of the monolithic $\mathrm{Al}_{2} \mathrm{O}_{3}$ and the GPLs/ $/ \mathrm{Al}_{2} \mathrm{O}_{3}$ nanocomposites in the in-plane and through thickness directions as a function of the GPLs content. $\varphi_{c}, t_{c}$ and $\sigma_{0}$ parameters were determined for both in-plane and throughthickness directions by fitting the experimental data to Eq. (2) (the red solid lines in Fig. 8). The fitting parameters are shown in Table 4. The log-log plots of $\sigma$ versus $\left(\varphi-\varphi_{\mathrm{c}}\right)$ shown in the inset of Fig. 8 reveal linear relationships indicating a good fit $\left(R^{2}\right.$ is 0.992 and 0.998 for the in-plane and through-thickness directions, respectively). Fig. 8 shows that the monolithic $\mathrm{Al}_{2} \mathrm{O}_{3}$ and the nanocomposites with GPLs contents up to 7 vol.\% exhib-

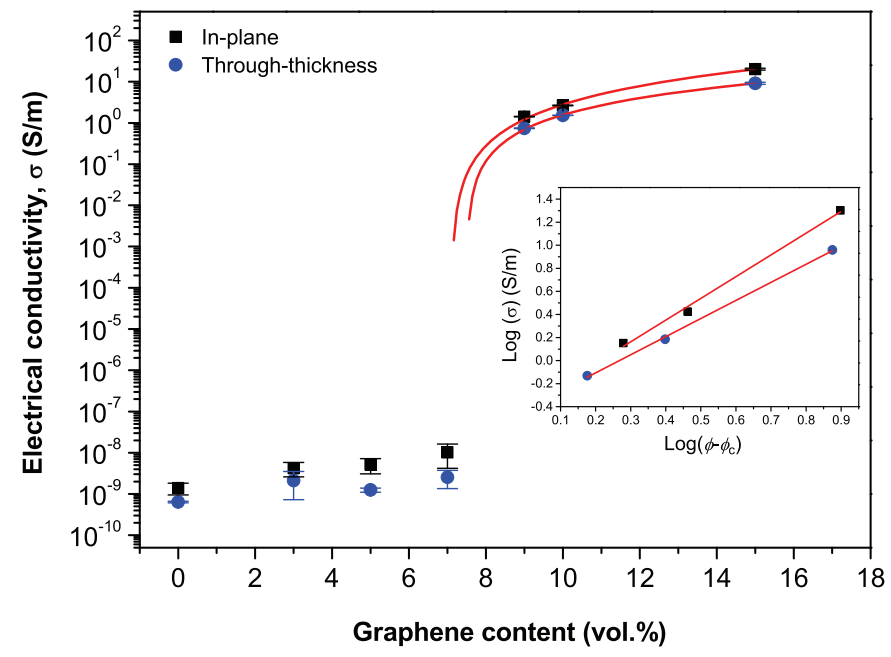

Fig. 8. In-plane and through-thickness electrical conductivities of GPLs/ $/ \mathrm{Al}_{2} \mathrm{O}_{3}$ nanocomposites at room temperature. The solid lines are fittings to Eq. (2). Inset is the double-logarithmic plot of electrical conductivity versus $\left(\varphi-\varphi_{c}\right)$, showing a linear relationship $\left(R^{2}\right.$ is 0.992 and 0.998 for the in-plane and through-thickness directions, respectively).

Table 4

Fitting parameters of the electrical conductivity data depending on the GPLs content determined both in the in-plane and through-thickness directions by fitting the experimental data to the classical percolation theory (Eq. (2)).

\begin{tabular}{lccll}
\hline & $\sigma_{0}$ & $\varphi_{\mathrm{c}}$ & $t_{\mathrm{c}}$ & $\operatorname{Adj} R^{2}$ \\
\hline In-plane & $0.343 \pm 0.56$ & $7.1 \pm 1.36$ & $1.97 \pm 0.62$ & 0.9993 \\
Through-thickness & $0.360 \pm 0.18$ & $7.5 \pm 0.46$ & $1.60 \pm 0.2$ & 0.9997 \\
\hline
\end{tabular}

ited insulating behavior with electrical conductivities in the range of $\sim 10^{-10}-10^{-8} \mathrm{~S} / \mathrm{m}$. When the GPLs amount was increased to 9 vol.\%, the electrical conductivity increased sharply by $\sim 9$ orders of magnitude compared to the monolithic $\mathrm{Al}_{2} \mathrm{O}_{3}$ leading to an electrically conductive nanocomposite with 1.42 and $0.74 \mathrm{~S} / \mathrm{m}$ conductivity values in the in-plane and through-thickness directions, respectively. This increase is attributed to formation of a conductive network by interconnected GPLs resulting in an electrical percolation. The fittings of the experimental data gave percolation threshold $\left(\varphi_{\mathrm{c}}\right)$ of $\sim 7.1 \pm 1.36$ and $\sim 7.5 \pm 0.46$ vol.\% for the in-plane and through-thickness directions, respectively, revealing that preferential orientation of GPLs has not affected the percolation threshold much, as in agreement with Ramirez et al. [12] who reported similar $\varphi_{\mathrm{c}}$ values to those observed in the present study. It should be noted that GPLs loadings higher than the percolation threshold extended the improvement of the electrical conductivity (Fig. 8). This phenomenon is in agreement with previous studies $[11,17,30]$ and could be attributed to an increase in the number of interconnections between GPLs with increasing GPLs amount.

Even though there is an obvious preferential orientation of GPLs throughout the matrix as it was confirmed by the SEM micrographs and Raman analyses, the electrical conductivity of the nanocomposites exhibited a slight anisotropy depending on the orientation of GPLs with a slightly lower resistivity in the in-plane direction. The in-plane conductivity of the nanocompos- 
ites is $\sim 2-3 \times$ of the conductivity in through-thickness direction. The lower anisotropy than expected could be attributed to the presence of some misaligned/rotated GPLs with respect to the alignment plane (in-plane direction) of most of the GPLs which oriented during SPS process, as suggested by Ramirez et al. [12], who reported in-plane to through-thickness electrical conductivity ratio of $10-25$ for their GPLs/ $\mathrm{Si}_{3} \mathrm{~N}_{4}$ composites. Moreover, the electrical conductivity of a composite can be improved by filler material either through establishing a new conductive path in the matrix or through increasing the cross area of the formed path, which is the thickness of graphene flakes in case of graphene-based nanocomposites [30]. At high graphene-based material loadings, the probability of agglomeration and overlapping increases resulting in an increment in the thickness of graphene flakes [30]. In this case, second mechanism becomes dominant and the electrical conductivity increases in the through-thickness direction, as well as in the in-plane direction. This phenomenon is also supposed to be effective in the relatively low anisotropy observed for the electrical conductivity of the GPLs $/ \mathrm{Al}_{2} \mathrm{O}_{3}$ nanocomposites. Thin few-layer graphene flakes, which locate at the grain boundaries and around the matrix grains, could also affect the anisotropy in the electrical conductivity. The fitting of the experimental data yielded $t_{\mathrm{c}}$ values of $1.97 \pm 0.62$ and $1.60 \pm 0.2$ for the in-plane and through-thickness directions, respectively. The $t_{\mathrm{c}}$ value determined for the in-plane direction is in excellent fit with the expected value $(\sim 1.94)$ for three-dimensional percolating systems indicating the three-dimensional network of GPLs in the nanocomposites above the percolation threshold. This result is in agreement with the relatively low anisotropy in electrical conductivity and with similar $\varphi_{\mathrm{c}}$ values observed in both directions. The lower $t_{\mathrm{c}}$ value observed for the through-thickness direction in comparison to the in-plane direction could be attributed to a percolation which takes place in a network with more 'dead arms' or weakly connected parts than a classical random network [1,3] or to a quasi-two-dimensional network of GPLs with a combination of two- and three-dimensional organizations. Fan et al. [17] reported $t_{c}$ value of 1.54 for the $\mathrm{GPLs} / \mathrm{Al}_{2} \mathrm{O}_{3}$ composites and attributed the low value of $t_{\mathrm{c}}$ to some preferential orientation of GPLs in the in-plane direction. However, the authors did not make any orientation dependent measurements [17]. Ramirez et al. [12] estimated $t_{\mathrm{c}}=0.89$ and $t_{\mathrm{c}}=2.05$ for the inplane and through-thickness electrical conductivity data of their GPLs/Si ${ }_{3} \mathrm{~N}_{4}$ composites and attributed the observation of larger $t_{\mathrm{c}}$ exponent for the through-thickness direction compared to the in-plane direction to a broader range of inter-particle connectivity.

The maximum electrical conductivities achieved in the present study are $\sim 20.1$ and $\sim 9.1 \mathrm{~S} / \mathrm{m}$ for the 15 vol.\% GPLs $/ \mathrm{Al}_{2} \mathrm{O}_{3}$ nanocomposite in the in-plane and through-thickness directions, respectively (Fig. 8). Although these values are sufficiently high for EDM process, they are much lower than the one reported by Fan et al. [17], who achieved $5709 \mathrm{~S} / \mathrm{m}$ electrical conductivity for the same amount of graphene-based material in the $\mathrm{Al}_{2} \mathrm{O}_{3}$ matrix. This difference can be attributed to the preferential orientation of graphene flakes throughout the matrix which may raise the percolation threshold [4], and also to different characteristics of the graphene-based materials used for the composite production, such as lower lateral size and aspect ratio which may affect the percolation threshold and electrical conductivity. Fan et al. [17] used ball milling to grind expanded graphite with $\mathrm{Al}_{2} \mathrm{O}_{3}$ and obtained graphene-based material with mostly $\sim 2.5-20 \mathrm{~nm}$ in thickness; however, they did not give information about the lateral size of these flakes. The GPLs utilized in the present study are small in lateral size (mostly $<1 \mu \mathrm{m}$ ) and it is known that smaller graphene flakes result in more junctions and consequently in lower conductivity due to the effect of inter-flake junction resistances [31,32]. Moreover, higher amount of GPLs is required to form a conductive network when flakes

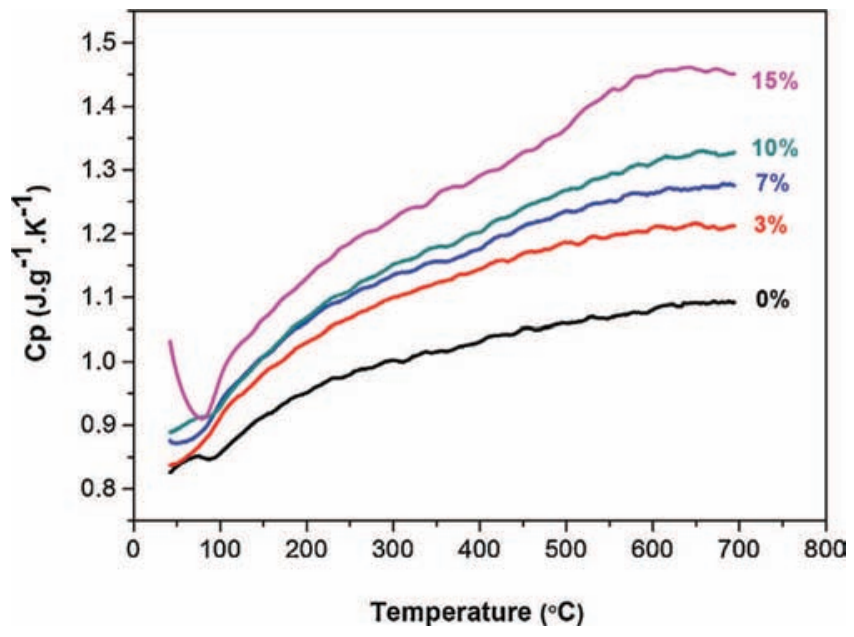

Fig. 9. Specific heat values of the monolithic $\mathrm{Al}_{2} \mathrm{O}_{3}$ and the GPLs/ $/ \mathrm{Al}_{2} \mathrm{O}_{3}$ nanocomposites (a) experimental values.

with a smaller lateral size are used. Recently, Fan et al. [30] produced few-layer graphene $(<5 \mathrm{~nm}) / \mathrm{Al}_{2} \mathrm{O}_{3}$ nanocomposites by spark plasma sintering of graphene oxide $/ \mathrm{Al}_{2} \mathrm{O}_{3}$ hybrids prepared by colloidal processing with a simultaneous reduction of GO. The authors achieved a percolation threshold as low as 0.38 vol.\% and obtained a conductivity of $1038.15 \mathrm{~S} / \mathrm{m}$ by increasing the graphene content to $2.35 \mathrm{vol} . \%$ [30]. They attributed this lower percolation to homogeneous dispersion of very thin few-layer graphene in the matrix, high quality of the as prepared few-layer graphene and to better contact between conductive nanoparticles [30]. If compared with CNT containing systems, Rul et al. [1] prepared SWNT- $\mathrm{MgAl}_{2} \mathrm{O}_{4}$ composites with a homogeneous distribution of SWNTs between matrix grains by in-situ catalytic chemical vapor deposition method. They investigated the electrical conductivity of the composites with 0.23 and 24.5 vol.\% CNT content and reported a percolation threshold of $0.64 \mathrm{vol} . \%$ and a conductivity of $0.4-850 \mathrm{~S} / \mathrm{m}$ depending on the CNT content [1]. Zhan et al. [33] reported electrical conductivity of $3345 \mathrm{~S} / \mathrm{m}$ for 15 vol.\% SWNT containing $\mathrm{Al}_{2} \mathrm{O}_{3}$ nanocomposite.

\subsection{Thermal properties}

Thermal properties of the GPLs $/ \mathrm{Al}_{2} \mathrm{O}_{3}$ nanocomposites were investigated as a function of temperature, graphene content and orientation of GPLs in the matrix. Fig. 9 shows the $C_{p}$ values of the monolithic $\mathrm{Al}_{2} \mathrm{O}_{3}$ and the GPLs/ $/ \mathrm{Al}_{2} \mathrm{O}_{3}$ nanocomposites as a function of temperature determined by DSC measurements. The $C_{p}$ of all the samples increased with temperature (Fig. 9). Heat is generally stored by phonons and free electrons of a material; however, for graphite and graphene, phonons dominate the specific heat at all practical temperatures $(>1 \mathrm{~K})$, and the phonon specific heat increases with temperature [34,35]. Fig. 9 reveals that the $C_{p}$ values increase with graphene addition, as in agreement with Miranzo et al. [9]. Similar behavior was also reported by Kumari et al. [36] for the $\mathrm{CNT}-\mathrm{Al}_{2} \mathrm{O}_{3}$ nanocomposite systems, the heat capacity of which is much higher than that of the monolithic $\mathrm{Al}_{2} \mathrm{O}_{3}$.

The thermal conductivity of the monolithic $\mathrm{Al}_{2} \mathrm{O}_{3}$ and the GPLs $/ \mathrm{Al}_{2} \mathrm{O}_{3}$ nanocomposites decreased with increasing temperature both in the in-plane and the through-thickness directions (Fig. 10). This behavior is characteristic of crystalline solids and is attributed to phonon-phonon Umklapp scattering, which makes major contribution to thermal conductivity at high temperatures as reducing the phonon mean free path [36-38]. In through-thickness direction, the monolithic $\mathrm{Al}_{2} \mathrm{O}_{3}$ exhibited higher thermal conductivity than that of the GPLs/ $/ \mathrm{Al}_{2} \mathrm{O}_{3}$ nanocomposites within the measured temperature range, and the thermal conductivity values 

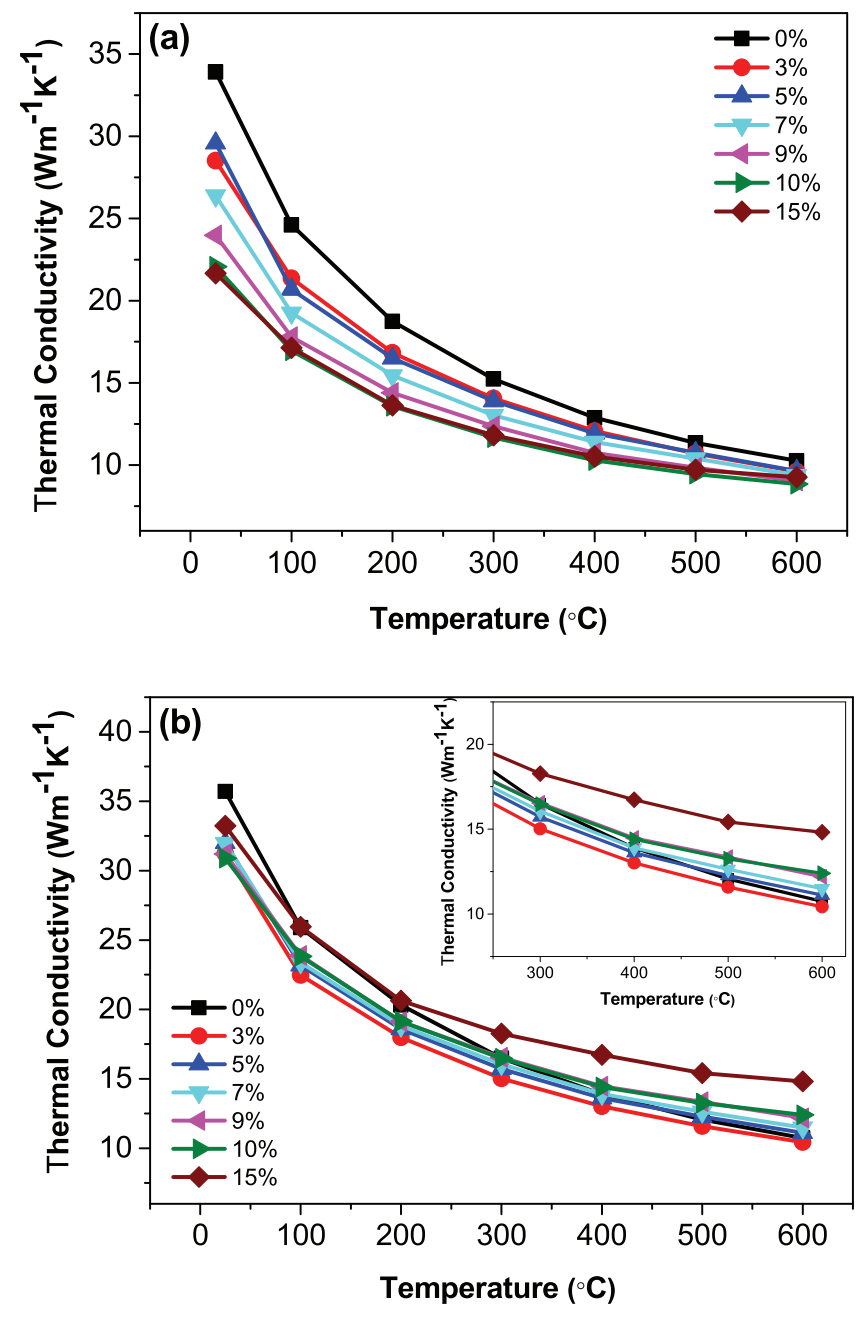

Fig. 10. Through-thickness (a) and in-plane (b) thermal conductivities of the monolithic $\mathrm{Al}_{2} \mathrm{O}_{3}$ and the GPLs/ $/ \mathrm{Al}_{2} \mathrm{O}_{3}$ nanocomposites as a function of temperature.

decreased with increasing GPLs amount (Fig. 10a). The decrease in the thermal conductivity of monolithic $\mathrm{Al}_{2} \mathrm{O}_{3}$ with GPLs addition could be attributed mainly to interfacial thermal resistance between GPLs and $\mathrm{Al}_{2} \mathrm{O}_{3}$ grains [37-39]. Although graphene has extremely high intrinsic thermal conductivity in its suspended form ( $\sim 5000 \mathrm{~W} \mathrm{~m}^{-1} \mathrm{~K}^{-1}$ at room temperature) [40], the final thermal properties of its potential applications, such as nanocomposites, are strongly affected by the interfacial thermal barrier. Interfacial thermal resistance, also known as thermal boundary resistance, at the interface of graphene with other materials, has a non-zero value even at the perfect interfaces owing to differences in the phonon density of states [38]. This effect is known as Kapitza resistance [41]. The actual thermal boundary resistance is usually higher than the Kapitza resistance owing to interface imperfections. Graphene thermal coupling to other materials depend on the surface roughness, presence or absence of suspended regions in graphene layers, and methods of graphene preparation [38]. Thermal expansion coefficient mismatch between the $\mathrm{Al}_{2} \mathrm{O}_{3}$ matrix and the graphene platelets might have caused a thermal stress leading to a separation at the interface forming gaps. This leads to an increase in the contact resistance and a decrease in the effective heat dissipation [42]. Moreover, as shown in Fig. 3, GPLs addition into monolithic $\mathrm{Al}_{2} \mathrm{O}_{3}$ led to a much finer microstructure; consequently, the amount of grain boundaries and interfaces, which act as scattering regions for phonons leading to a reduction in lattice thermal conductivity, increased. Interfacial thermal resistance decreases with tempera- ture following a typical trend for Kapitza resistance [38]. This could be the reason of the reduced difference within the thermal conductivity values of the monolithic $\mathrm{Al}_{2} \mathrm{O}_{3}$ and the nanocomposites with increasing temperature in through-thickness direction (Fig. 10a). The contacts between GPLs, the defects within GPLs and the presence of the bended GPLs at the $\mathrm{Al}_{2} \mathrm{O}_{3}$ grain boundaries also limit the thermal transport in the through-thickness direction [9]. In the in-plane direction, the thermal conductivity of the GPLs/ $/ \mathrm{Al}_{2} \mathrm{O}_{3}$ nanocomposites were slightly lower than that of the monolithic $\mathrm{Al}_{2} \mathrm{O}_{3}$ at room temperature; however, they showed an increasing trend with GPLs content (Fig. 10b). At higher temperatures, these values got closer to or even exceeded the thermal conductivity values of the monolithic $\mathrm{Al}_{2} \mathrm{O}_{3}$ depending on the volume fraction of GPLs, which could be attributed to a decrease in interfacial thermal resistance at high temperatures. The thermal conductivity curves of the monolithic $\mathrm{Al}_{2} \mathrm{O}_{3}$ and the $15 \mathrm{vol} . \% \mathrm{GPLs} / \mathrm{Al}_{2} \mathrm{O}_{3}$ nanocomposite coincided at $100^{\circ} \mathrm{C}$, and above that temperature the thermal conductivity of the $15 \mathrm{vol} \% \mathrm{GPLs} / \mathrm{Al}_{2} \mathrm{O}_{3}$ nanocomposite got higher than that of the monolithic $\mathrm{Al}_{2} \mathrm{O}_{3}$ and the difference between them increased with temperature (Fig. 10b). It is very clear that GPLs form a less resistive heat conduction path in the in-plane direction as expected, since the in-plane (parallel to basal plane) thermal conductivity of a graphene sheet is much higher (over 100-fold) than that of graphite crystals along the $c$-axis (perpendicular to basal plane) [43]. This result is in agreement with Miranzo et al. [9], who studied the thermal conduction of $\mathrm{Si}_{3} \mathrm{~N}_{4}$ composites with different types of carbon nanostructures (CNTs and GPLs) and investigated the effect of nanostructure orientation with respect to heat flux, testing temperature and $\alpha / \beta \mathrm{Si}_{3} \mathrm{~N}_{4}$ phase ratio. The authors reported that the addition of both CNTs and GPLs reduced the thermal conductivity in the through-thickness direction, and they obtained a significant improvement in the in-plane thermal conductivity for platelets addition up to $40 \mathrm{~W} \mathrm{~m}^{-1} \mathrm{~K}^{-1}$, twice the thermal conductivity of the $\mathrm{Si}_{3} \mathrm{~N}_{4}$ matrix [9]. Rutkowski et al. [10] reported that they obtained orientated GPLs in perpendicular direction to pressing axis in hot pressed samples, while not much anisotropy was achieved in composites prepared by SPS. This could be related to the relatively low pressure ( $35 \mathrm{MPa}$ ) that they applied during SPS process. Due to the lack of anisotropy, the thermal conductivity in perpendicular direction to pressing axis was lower than that of monolithic alumina and also lower than values measured in pressing direction (for the same GPLs amount) for GPLs contents $<10 \mathrm{wt} \%$ ( $\sim 16.8$ vol.\%). In the only study which investigated both the in-plane and through thickness thermal conductivity of CNTs containing ceramic nanocomposites, Zhan and Mukherjee [37] observed that incorporation of single-wall CNT ropes did not change the in-plane thermal diffusivity of the $\mathrm{Al}_{2} \mathrm{O}_{3}$, while it decreased the thermal diffusivity in the through-thickness direction.

Fig. 11a shows the in-plane thermal conductivity values of the nanocomposites as a function of GPLs volume fraction at $600^{\circ} \mathrm{C}$. From 3 vol.\% GPLs, the thermal conductivity increased almost linearly with graphene content without showing any clear thermal percolation threshold, in agreement with the observations of Shahil and Balandin for the multilayer graphene-epoxy composite systems [44]. $44 \%$ increase in the in-plane thermal conductivity at $600^{\circ} \mathrm{C}$ was achieved with $15 \mathrm{vol} . \%$ GPLs addition into the monolithic $\mathrm{Al}_{2} \mathrm{O}_{3}$ (Fig. 11a). The difference between the thermal and the electrical transport behaviors mainly arises from differences in conductivity ratios of filler to matrix [39]. The effective conduction path is through the filler material in case of electrical conductivity; however, heat can also be transmitted through the matrix [39], indicating that thermal conductivity is a bulk property, while electrical conductivity is a line property. The anisotropy between the in-plane and through-thickness thermal conductivities increased with GPLs amount. This anisotropy increase arises from decrement 

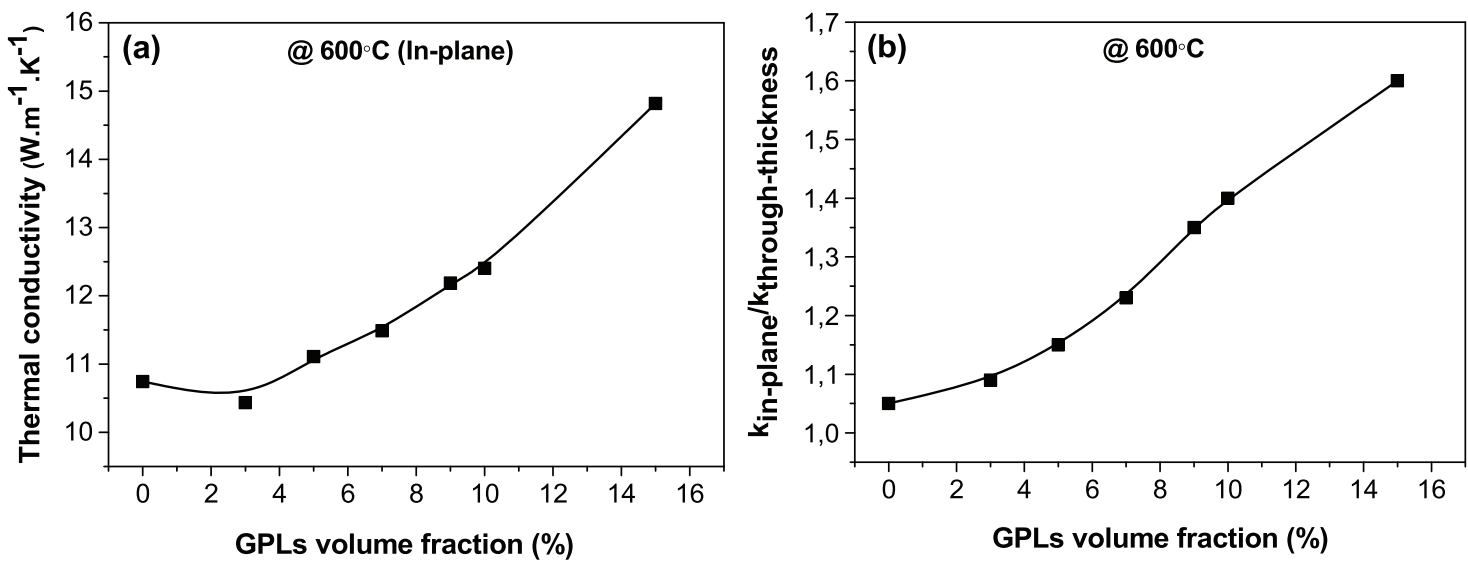

Fig. 11. (a) In-plane thermal conductivity of GPLs $/ \mathrm{Al}_{2} \mathrm{O}_{3}$ nanocomposites at $600{ }^{\circ} \mathrm{C}$ as a function of graphene content (vol.\%), (b) in-plane to through-thickness thermal conductivity ratio at $600{ }^{\circ} \mathrm{C}$ for the GPLs/ $/ \mathrm{Al}_{2} \mathrm{O}_{3}$ nanocomposites depending on the GPLs content (vol.\%).

of through-thickness thermal conductivity and improvement of inplane thermal conductivity simultaneously with increasing GPLs content. The intrinsic anisotropy in thermal expansion coefficient and thermal conductivity of graphene sheets [43] is expected to be effective in the less resistive heat dissipation in the in-plane direction. Fig. 11b shows the in-plane to through-thickness thermal conductivity ratio $\left(k_{\text {in-plane }} / k_{\text {through-thickness }}\right)$ at $600^{\circ} \mathrm{C}$ for the GPLs $/ \mathrm{Al}_{2} \mathrm{O}_{3}$ nanocomposites depending on the GPLs content. $\sim 52 \%$ increase in the $k_{\text {in-plane }} / k_{\text {through-thickness }}$ ratio was observed for the 15 vol.\% GPLs $/ \mathrm{Al}_{2} \mathrm{O}_{3}$ nanocomposite in comparison to the monolithic $\mathrm{Al}_{2} \mathrm{O}_{3}$ at $600{ }^{\circ} \mathrm{C}$ (Fig. $11 \mathrm{~b}$ ). Similar $k_{\text {in-plane }} / k_{\text {through-thickness }}$ ratios were also observed for the room temperature thermal conductivity values. Thermo-gravimetric analysis of the $15 \mathrm{vol} . \%$ GPLs $/ \mathrm{Al}_{2} \mathrm{O}_{3}$ nanocomposite was performed by heating it in air up to $1000^{\circ} \mathrm{C}$ with a heating rate of $10^{\circ} \mathrm{C} / \mathrm{min}$ in order to investigate its stability in air, and it was observed that the sample is stable up to $\sim 700^{\circ} \mathrm{C}$.

The higher in-plane thermal conductivity can be beneficial for dissipation of heat from one direction. The improvement in high temperature thermal conductivity can be advantageous to minimize heat accumulation in material during applications, such as cutting tools, where the material is exposed to high loads at high temperatures.

\section{Conclusions}

GPLs containing $\mathrm{Al}_{2} \mathrm{O}_{3}$ nanocomposites with anisotropic mechanical, thermal and electrical properties due to preferential orientation of GPLs throughout the matrix were prepared by SPS.

3 vol.\% GPLs addition into monolithic $\mathrm{Al}_{2} \mathrm{O}_{3}$ resulted in an increase in fracture toughness by $\sim 26.7 \%$ in the in-plane direction and a decrease by $\sim 17.2 \%$ in through thickness direction depending on the interface strength between GPLs and matrix grains. Pull-out is the main toughening mechanism in the in-plane direction for this nanocomposite. Further increase in GPLs content decreased the inplane fracture toughness due to weakening of the interface as a result of agglomeration/overlapping of GPLs, while increasing it in the through-thickness direction as a result of crack bridging and crack deflection mechanisms. Crack branching appeared at high GPLs loadings as a dominant toughening mechanism, especially for the 15 vol.\% GPLs containing nanocomposite resulting in $~ 10 \%$ and $\sim 33 \%$ increase in fracture toughness in through-thickness direction compared to the monolithic $\mathrm{Al}_{2} \mathrm{O}_{3}$ and the 3 vol.\% GPLs containing $\mathrm{Al}_{2} \mathrm{O}_{3}$, respectively. The toughening mechanisms observed in the GPLs $/ \mathrm{Al}_{2} \mathrm{O}_{3}$ nanocomposites depending on GPLs orientation and GPLs content are summarized in Fig. 12.

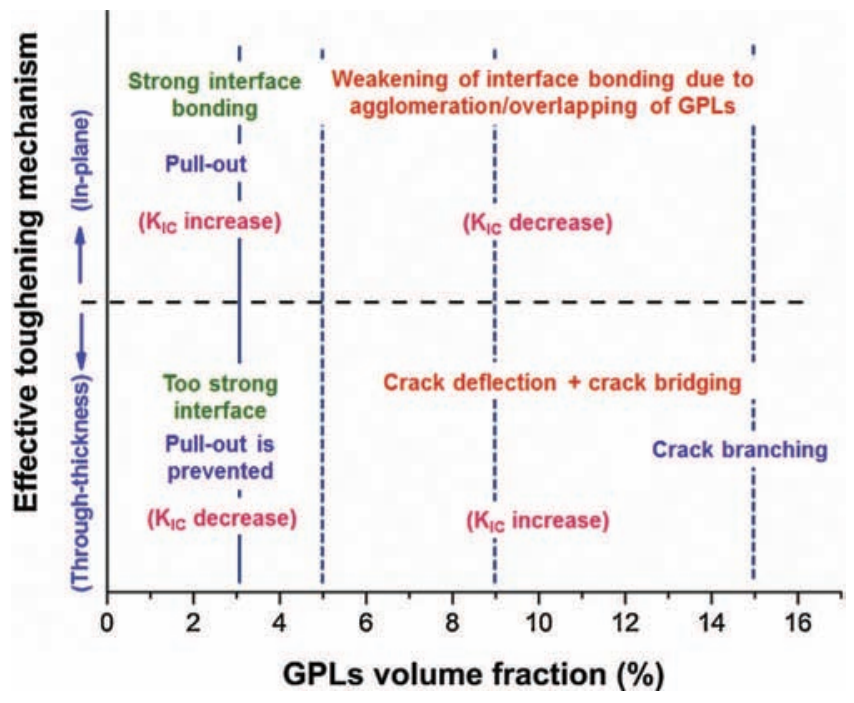

Fig. 12. Summary of the suggested toughening mechanisms in $\mathrm{GPLs} / \mathrm{Al}_{2} \mathrm{O}_{3}$ nanocomposites depending on GPLs content.

The electrical conductivity of the nanocomposites exhibited a slight anisotropy with a lower resistivity in the in-plane direction. An electrical percolation threshold was observed at $\sim 7.1$ and $\sim 7.5$ vol.\% GPLs contents for the in-plane and through-thickness directions, respectively. The electrical conductivity values of the 15 vol.\% GPLs containing $\mathrm{Al}_{2} \mathrm{O}_{3}$ nanocomposite are 20.1 and $9.1 \mathrm{~S} / \mathrm{m}$ in the in-plane and through-thickness directions, respectively, which are sufficiently high for EDM process.

Oriented GPLs also led to a less resistive heat conduction path in the in-plane direction. The thermal conductivity values of nanocomposites in the in-plane direction got higher than that of the monolithic $\mathrm{Al}_{2} \mathrm{O}_{3}$ at high temperatures $\left(>100^{\circ} \mathrm{C}\right)$, especially for high GPLs loadings. The anisotropy in thermal conductivity increased with GPLs amount. $44 \%$ increase in the in-plane thermal conductivity was achieved at $600^{\circ} \mathrm{C}$ with 15 vol.\% GPLs addition into the monolithic $\mathrm{Al}_{2} \mathrm{O}_{3}$ and this resulted in $\sim 52 \%$ increase in the $k_{\text {in-plane }} / k_{\text {through-thickness }}$ ratio.

\section{Acknowledgment}

The financial support for this study by Anadolu University Scientific Research Projects Commission (under the project numbers of 1110F155 and 1101F005) is gratefully acknowledged. 


\section{References}

[1] S. Rul, F. Lefevre-schlick, E. Capria, C. Laurent, A. Peigney, Percolation of single-walled carbon nanotubes in ceramic matrix nanocomposites, Acta Mater. 52 (2004) 1061-1067.

[2] E. Flahaut, A. Peigney, C. Laurent, C. Marliere, F. Chastel, A. Rousset, Carbon nanotube-metal-oxide nanocomposites: Microstructure, electrical conductivity and mechanical properties, Acta Mater. 48 (2000) 3803-3812.

[3] S. Barrau, P. Demont, A. Peigney, C. Laurent, C. Lacabanne, DC and AC conductivity of carbon nanotubes-polyepoxy composites, Macromolecules 36 (2003) 5187-5194.

[4] J.R. Potts, D.R. Dreyer, C.W. Bielawski, R.S. Ruoff, Graphene-based polymer nanocomposites, Polymer 52 (2011) 5-25.

[5] T.K. Das, S. Prusty, Graphene-based polymer composites and their applications, Polym. Plast. Technol. 52 (2013) 319-331.

[6] H.J. Kim, S.M. Lee, Y.S. Oh, Y.H. Yang, Y.S. Lim, D.H. Yoon, C. Lee, J.Y. Kim, R.S Ruoff, Unoxidized graphene/alumina nanocomposite: fracture- and wear-resistance effects of graphene on alumina matrix, Sci. Rep. 4 (2014) 5176.

[7] O. Malek, J. Gonzalez-Julian, J. Vleugels, W. Vanderauwera, B. Lauwers, M. Belmonte, Carbon nanofillers for machining insulating ceramics, Mater. Today 14 (2011) 496-501.

[8] H. Porwal, S. Grasso, M.J. Reece, Review of graphene-ceramic matrix composites, Adv. Appl. Ceram. 112 (2013) 443-454.

[9] P. Miranzo, E. Garcia, C. Ramirez, J. Gonzalez-Julian, M. Belmonte, M.I. Osendi, Anisotropic thermal conductivity of silicon nitride ceramics containing carbon nanostructures, J. Eur. Ceram. Soc. 32 (2012) 1847-1854.

[10] P. Rutkowski, P. Klimczyk, L. Jaworska, L. Stobierski, A. Dubiel, Thermal properties of pressure sintered alumina-graphene composites, J. Therm. Anal. Calorim. (2015) 1-10.

[11] A. Centeno, V.G. Rocha, B. Alonso, A. Fernandez C.F. Gutierrez-Gonzalez R. Torrecillas, A. Zurutuza, Graphene for tough and electroconductive alumina ceramics, J. Eur. Ceram. Soc. 33 (2013) 3201-3210.

[12] C. Ramirez, F.M. Figueiredo, P. Miranzo, P. Poza, M.I. Osendi, Graphene nanoplatelet/silicon nitride composites with high electrical conductivity, Carbon 50 (2012) 3607-3615.

[13] L.S. Walker, V.R. Marotto, M.A. Rafiee, N. Koratkar, E.L. Corral, Toughening in Graphene Ceramic Composites, ACS Nano 5 (2011) 3182-3190.

[14] A. Evans, E. Charles, Fracture toughness determinations by indentation, J. Am. Ceram. Soc. 59 (1976) 371-372

[15] W. Parker, R. Jenkins, C. Butler, G. Abbott, Flash method of determining thermal diffusivity heat capacity, and thermal conductivity, J. Appl. Phys. 32 (1961) 1679-1684.

[16] I.A. Ovid'ko, A.G. Sheinerman, Micromechanisms for improved fracture toughness in nanoceramics, Rev, Adv Mater. Sci. 29 (2011) 105-125.

[17] Y.C. Fan, L.J. Wang, J.L. Li, J.Q. Li, S.K. Sun, F. Chen, L.D. Chen, W. Jiang, Preparation and electrical properties of graphene nanosheet $/ \mathrm{Al}_{2} \mathrm{O}_{3}$ composites, Carbon 48 (2010) 1743-1749.

[18] K. Wang, Y.F. Wang, Z.J. Fan, J. Yan, T. Wei, Preparation of graphene nanosheet/alumina composites by spark plasma sintering, Mater. Res. Bull. 46 (2011) 315-318.

[19] J. Dusza, J. Morgiel, A. Duszova, L. Kvetkova, M. Nosko, P. Kun, C. Balazsi, Microstructure and fracture toughness of $\mathrm{Si}_{3} \mathrm{~N}_{4}+$ graphene platelet composites, J. Eur. Ceram. Soc. 32 (2012) 3389-3397.

[20] Y.C. Fan, M. Estili, G. Igarashi, W. Jiang, A. Kawasaki, The effect of homogeneously dispersed few-layer graphene on microstructure and mechanical properties of $\mathrm{Al}_{2} \mathrm{O}_{3}$ nanocomposites, J. Eur. Ceram. Soc. 34 (2014) $443-451$.

[21] D. Richerson, Modern Ceramic Engineering: Properties, Processing, and Use in Design, second ed., Marcel Dekker Inc., 1992.
[22] J. Liu, H.X. Yan, K. Jiang, Mechanical properties of graphene platelet-reinforced alumina ceramic composites, Ceram. Int. 39 (2013) 6215-6221.

[23] M.S. Dresselhaus, A. Jorio, M. Hofmann, G. Dresselhaus, R. Saito, Perspectives on carbon nanotubes and graphene Raman spectroscopy, Nano Lett. 10 (2010) $751-758$.

[24] A. Das, S. Pisana, B. Chakraborty, S. Piscanec, S.K. Saha, U.V. Waghmare, K.S. Novoselov, H.R. Krishnamurthy, A.K. Geim, A.C. Ferrari, A.K. Sood, Monitoring dopants by Raman scattering in an electrochemically top-gated graphene transistor, Nat. Nanotechnol. 3 (2008) 210-215.

[25] S. Pisana, M. Lazzeri, C. Casiraghi, K.S. Novoselov, A.K. Geim, A.C. Ferrari, F. Mauri, Breakdown of the adiabatic Born-Oppenheimer approximation in graphene, Nat. Mater. 6 (2007) 198-201.

[26] S. Kirkpatrick, Percolation and conduction, Rev. Mod. Phys. 45 (1973) 574-588.

[27] D. Stauffer, A. Aharony, Introduction to percolation theory, second ed., Taylor \& Francis, London, 1994

[28] Nanocomposites, Nanophotonics, Nanobiotechnology and Applications, in: O. Fesenko, L. Yatsenko (Eds.), Proceedings in Physics, Springer, 2015, p. 156.

[29] S.D. Littlejohn, Electrical properties of graphite nanoparticles in silicone: flexible oscillators and electromechanical sensing, in: Theses, Springer, 2014.

[30] Y.C. Fan, W. Jiang, A. Kawasaki, Highly conductive few-layer graphene $/ \mathrm{Al}_{2} \mathrm{O}_{3}$ nanocomposites with tunable charge carrier type, Adv. Funct. Mater. 22 (2012) 3882-3889.

[31] U. Khan, A. O'Neill, H. Porwal, P. May, K. Nawaz, J.N. Coleman, Size selection of dispersed, exfoliated graphene flakes by controlled centrifugation, Carbon 50 (2012) 470-475.

[32] P.E. Lyons, S. De, F. Blighe, V. Nicolosi, L.F.C. Pereira, M.S. Ferreira, J.N. Coleman, The relationship between network morphology and conductivity in nanotube films, J. Appl. Phys. 104 (2008) 044302.

[33] G.D. Zhan, J.D. Kuntz, J.E. Garay, A.K. Mukherjee, Electrical properties of nanoceramics reinforced with ropes of single-walled carbon nanotubes, Appl Phys. Lett. 83 (2003) 1228-1230.

[34] E. Pop, V. Varshney, A.K. Roy, Thermal properties of graphene: Fundamentals and applications, MRS Bull. 37 (2012) 1273-1281.

[35] J. Hone, Phonons and thermal properties of carbon nanotubes, in: M. Dresselhaus, G. Dresselhaus, P. Avouris (Eds.), Carbon Nanotubes, vol. 80, Springer, Berlin Heidelberg, 2001, pp. 273-286.

[36] L. Kumari, T. Zhang, G.H. Du, W.Z. Li, Q.W. Wang, A. Datye, K.H. Wu, Thermal properties of CNT-alumina nanocomposites, Compos. Sci. Technol. 68 (2008) 2178-2183.

[37] G.D. Zhan, A.K. Mukherjee, Carbon nanotube reinforced alumina-based ceramics with novel mechanical electrical, and thermal properties, Int. J. Appl. Ceram. Tecnol. 1 (2004) 161-171.

[38] A.A. Balandin, Thermal properties of graphene and nanostructured carbon materials, Nat. Mater. 10 (2011) 569-581.

[39] K. Ahmad, W. Pan, Electrical, mechanical, and thermal properties of multiwalled carbon nanotube reinforced alumina composites, in: S. Mathur, M. Singh (Eds.), Nanostructured Materials and Nanotechnology II: Ceramic Engineering and Science Proceedings, vol. 29, John Wiley \& Sons, Inc., 2008, pp. 49-59 (8).

[40] A.A. Balandin, S. Ghosh, W.Z. Bao, I. Calizo, D. Teweldebrhan, F. Miao, C.N. Lau, Superior thermal conductivity of single-layer graphene, Nano Lett. 8 (2008) 902-907.

[41] P.L. Kapitza, Collected Papers of P.L Kapitza, Pergamon Press, Oxford, 1965.

[42] S.R. Wang, M. Tambraparni, J.J. Qiu, J. Tipton, D. Dean, Thermal expansion of graphene composites, Macromolecules 42 (2009) 5251-5255.

[43] I.L. Shabalin, Ultra-high temperature materials I: carbon (graphene/graphite) and refractory metals, Springer, London, 2014.

[44] K.M.F. Shahil, A.A. Balandin, Thermal properties of graphene and multilayer graphene: applications in thermal interface materials, Solid State Commun. 152 (2012) 1331-1340. 